\title{
El procedimiento para la remunicipalización de servicios públicos. A propósito de los artículos 85 y 86 LRBRL
}

\section{The procedure for the remunicipalization of public services. On articles 85 and 86 of the Spanish Law on Local Government}

\author{
Miguel León Acosta \\ Universidad de Córdoba (España) \\ ORCID: https://orcid.org/0000-0001-5729-6832 \\ d32leacm@uco.es
}

\begin{abstract}
NOTA BIBLIOGRÁFICA
Doble Graduado en Derecho (2013-2018) y en Administración y Dirección de Empresas (2013-2019) por la Universidad de Córdoba. Actualmente ocupa el puesto de Técnico de Apoyo a la Investigación en el Área de Derecho Administrativo de la Universidad de Córdoba, a la cual ha estado estrechamente ligado como alumno colaborador. Hasta la fecha ha estudiado la intervención de la Administración en la actividad económica y la actividad administrativa de servicio público. En particular, ha estudiado el fenómeno de la remunicipalización de los servicios públicos locales, y los procedimientos que deben seguir las Entidades locales para ejercer la iniciativa pública local. De hecho. Su Trabajo Fin de Grado de Derecho tuvo por objeto "El procedimiento para la remunicipalización de los servicios públicos. Estudio doctrinal y jurisprudencial".
\end{abstract}

\section{RESUMEN}

El presente trabajo estudia la vertiente procedimental del fenómeno de la (re)municipalización entendida como la recuperación de la gestión directa de servicios públicos locales que fueron gestionados por una Entidad local y, posteriormente, confiados a la gestión privada. A tal efecto, se estudia, primero, la necesidad de seguir el procedimiento establecido en los artículos 86 de la Ley Reguladora de las Bases del Régimen Local y 97 del Texto Refundido del Régimen Local, relativo al ejercicio de actividades económicas; y, en segundo lugar, la incidencia de la Ley 27/2013, de 27 de diciembre, de racionalización y sostenibilidad de la Administración Local en el artículo 85 de la Ley Reguladora de las Bases del Régimen Local, donde se recogen los diferentes modos de gestión de los que dispone la Entidad local para prestar servicios públicos.

\section{PALABRAS CLAVE}

Remunicipalización; procedimiento; servicios públicos locales; gestión del servicio público.

\begin{abstract}
The present work analyses, from a procedural perspective, the phenomenon of (re)municipalization understood as the recovery of the direct management of local public services which were managed by a local entity and, afterwards, through private management. For this purpose, it is first analysed the need of following the procedure established in the articles 86 of the Spanish Law on Local Government, which deals with the exercise of economic activities; and, secondly, the influence of the Spanish Law on local financial sustainability on article 85 of the aforementioned Law on Local Government, where the different management methods to provide local public services by local entities are established.
\end{abstract}

\section{KEYWORDS}

Remunicipalisation; procedure; local public services; management of public services. 
REALA. Nueva Época - N.o 12, octubre-marzo 2019 - ISSN: 1989-8975 - DOI: 10.24965/reala.i12.10682 - [Págs. 72-96]

El procedimiento para la remunicipalización de servicios públicos. A propósito de los artículos 85 y 86 LRBRL

Miguel León Acosta

\begin{abstract}
SUMARIO
I. INTRODUCCIÓN. II. EL PROCEDIMIENTO DE LOS ARTÍCULOS 86 LRBRL Y 97 TRRL. 1. LOS TRÁMITES DEL PROCEDIMIENTO. 1.1. Para el ejercicio de «actividades económicas» por las Entidades locales. 1.2. Para el ejercicio de «actividades económicas» en régimen de monopolio. 2. SOBRE LA APLICACIÓN DE LOS ARTÍCULOS 86 LRBRL Y 97 TRRL A LA ACTIVIDAD ECONÓMICA DE LAS ENTIDADES LOCALES. 2.1. La aplicación del procedimiento de los artículos 86 LRBRL y 97 TRRL a la asunción de servicios públicos por parte de la Corporación local. 2.2. La aplicación del procedimiento de los artículos 86 LRBRL y 97 TRRL a los cambios de gestión en la prestación de servicios públicos. III. SOBRE LA GESTIÓN DEL SERVICIO PÚBLICO: EL ARTÍCULO 85 LRBRL. 1. LA REFORMA DEL ARTÍCULO 85 LRBRL Y LA REDUCCIÓN DE LA DISCRECIONALIDAD DE LA FORMA DE GESTIÓN. 1.1. Requisitos materiales del artículo 85 LRBRL: La sostenibilidad y eficiencia. 1.2. Requisitos formales del artículo 85 LRBRL. 2. CONSECUENCIAS DE LA REFORMA DEL ARTíCULO 85 LRBRL. 2.1. De una potestad discrecional a una potestad reglada. 2.2. ¿La preferencia por la gestión indirecta frente a la directa? IV. CONCLUSIONES. V. BIBLIOGRAFÍA.
\end{abstract}

\title{
I. INTRODUCCIÓN
}

Los servicios públicos, y la responsabilidad de los poderes públicos sobre su prestación, constituyen uno de los pilares fundamentales de los actuales Estados de Bienestar. Así lo han afirmado con rotundidad nuestros tribunales, señalando que «la Constitución Española en su artículo 1.1 establece que "España se constituye en un Estado social y democrático de derecho", y los servicios públicos, como actividad prestacional realizada por la Administración, en tanto reportan utilidades y beneficios a los ciudadanos, integran el contenido esencial de ese Estado social» ${ }^{1}$. Esta idea es aún más intensa en el ámbito local, donde los servicios públicos constituyen el núcleo central de las competencias municipales y «son la razón de ser, desde la perspectiva social, del Municipio mismo», utilizando las expresivas palabras de Ortega Bernardo².

Tradicionalmente se ha señalado que los servicios públicos podían clasificarse en dos grandes categorías: los servicios sociales o asistenciales -basados en la idea de solidaridad y cohesión social- y los servicios públicos económicos -que suponen la producción de bienes y servicios en un mercado, normalmente a cambio de una contraprestación económica-. El origen de estos últimos puede situarse en el contexto de la Revolución Industrial, cuando la invención de la máquina de vapor y la mecanización del campo produjeron un trasvase de mano de obra del mundo rural a la ciudad, generando «un importante crecimiento urbano que, a su vez, llevó al deterioro de las condiciones de vida en las ciudades, como resultado de la insuficiente provisión de servicios que devinieron esenciales» ${ }^{3}$.

A esta situación respondieron, no sin dificultades, los Municipios, asumiendo la prestación de estos incipientes servicios (públicos) de carácter económico: abastecimiento de agua potable, alumbrado por gas y luego por luz eléctrica, telefonía, transporte urbano, etc. En un primer momento, las Administraciones locales contrataron su provisión mediante privados, a través de la figura de los concesionarios interpuestos. Sin embargo, pronto surgieron problemas relacionados con la gestión privada de estos servicios y actividades, denunciándose «la incapacidad de las empresas privadas para poder satisfacer las necesidades colectivas esenciales que se vinculaban a esa vida social moderna, dada la distinta forma de actuar y los diversos fines que perseguían la gestión privada y la gestión pública» ${ }^{4}$. Por ello, muchos Municipios terminaron por asumir también la gestión de estos servicios.

Este proceso por el cual el Municipio asumió la responsabilidad de prestar este tipo de servicios y, más tarde, la gestión directa sobre los mismos se conoce como «municipalización de servicios públicos». Sobre él se discutió en toda Europa (Francia, Italia, Alemania y, en menor medida, España) entre finales del siglo XIX y el primer tercio del siglo XX, generando amplios debates, a favor y en contra ${ }^{5}$.

STSJ de Baleares 957/2010, de 29 de octubre (rec. 422/2005), FJ 3.

2 ORTEGA BERNARDO, J. (2006): "Competencias, servicios públicos y actividad económica de los Municipios: (Presupuestos actuales para su delimitación y su ejercicio)", en Revista de Administración Pública, núm. 169, pág. 57. En el mismo sentido MALARET I GARCIA, E. (2003): "Servicio público, actividad económica y competencia: ¿presenta especificidades la esfera local?", en Revista de Estudios de la Administración Local y Autonómica REALA, núm. 291, pág. 606.

3 MAGALDI, N. (2012): "La primera doctrina española sobre la municipalización de servicios públicos: en particular, la recepción de la doctrina extranjera por el profesor Gascón y Marín", en Revista Aragonesa de Administración Pública, núm. 39-40, pág. 167.

4 Ibidem, pág. 169.

5 Ibidem, págs. 182-186. 
REALA. Nueva Época - N.o 12, octubre-marzo 2019 - ISSN: 1989-8975 - DOI: 10.24965/reala.i12.10682 - [Págs. 72-96]

El procedimiento para la remunicipalización de servicios públicos. A propósito de los artículos 85 y 86 LRBRL

Miguel León Acosta

Sorprendentemente, más de un siglo después este debate se ha vuelto a poner sobre la mesa. En efecto, con la entrada de España en la Unión Europea se produjeron, en el ámbito estatal, numerosas liberalizaciones materiales, mientras que en el ámbito local fueron más comunes las privatizaciones organizativas, es decir, la externalización de los servicios públicos locales ${ }^{6}$, fenómeno que aumentó tras la crisis económica de 2008, como explican Ortega Bernardo y de Sande Pérez-Bedmar ${ }^{7}$. Frente a estas privatizaciones, que en muchos casos no han dado los resultados esperados ${ }^{8}$, ha surgido el movimiento conocido como la remunicipalización de servicios, al amparo sobre todo de fuerzas políticas de izquierdas ${ }^{9}$ y respaldado por parte de la opinión pública ${ }^{10}$ que defiende la bondad la gestión pública ${ }^{11}$. En concreto, este movimiento remunicipalizador aboga por la recuperación de la gestión de los servicios públicos locales que habían sido gestionados directamente por el Municipio y que fueron luego confiados a privados.

Como hemos ya señalado, el término municipalización fue utilizado en sus orígenes para describir el proceso por el que los Municipios dejaron de tener un papel pasivo en la vida ecónomica ${ }^{12}$ y comenzaron a asumir la responsabilidad de prestar servicios y actividades que devinieron esenciales en los núcleos urbanos a partir de la Revolución Industrial. Y ello, con independencia de cómo se gestionara el servicio en cuestión: a través de las primeras fábricas municipales (lo que hoy llamaríamos gestión directa) o mediante contratos con privados (que acabaría derivando en el luego denominado contrato de concesión de servicios públicos) ${ }^{13}$. Algo más tarde, el término pasó a utilizarse, también y sobre todo, para aludir a los supuestos en los que los entes locales asumieron directamente la gestión de aquellos servicios confiados a particulares.

Esta última acepción parece ser la que recoge el legislador en el aún (parcialmente) vigente Reglamento de Servicios de las Corporaciones Locales (en adelante, RSCL) aprobado por Decreto de 17 de junio de 1955. Su artículo 45 define «municipalización» como «forma de desarrollo de la actividad de las Corporaciones locales para la prestación de los servicios económicos de su competencia, asumiendo en todo o en parte el

${ }^{6}$ Sobre el posicionamiento favorable de la Unión Europea respecto a la cooperación público-privada véase GIMENO FELIU, J. M. (2017): "La remunicipalización de servicios públicos locales: la necesaria depuración de conceptos y los condicionantes jurídicos desde la óptica del derecho europeo", en Cuadernos de Derecho Local, QDL, núm. 43, págs. 47-49.

7 ORTEGA BERNARDO, J. y DE SANDE PÉREZ-BEDMAR, M. (2015): "El debate sobre la remunicipalización de los servicios públicos: aspectos jurídicos, administrativos y laborales", en Anuario de Derecho Municipal, núm. 9, pág. 64. Esta ola de privatizaciones se basó en la pretendida mayor eficiencia en términos económicos de la gestión desarrollada por empresas privadas, debido a la optimización de recursos, la mayor productividad y las ventajas de la libre concurrencia empresarial.

8 Vid. FEDERACIÓN SINDICAL EUROPEA DE SERVICIOS PÚBLICOS (EPSU) (2012): Por qué el agua es un servicio público: destapando los mitos de la privatización. Unidad de Investigación Internacional de Servicios Públicos (PSIRU) de la Universidad de Greenwich. En este trabajo, más politológico que jurídico, se concluye que la gestión privada no ha demostrado ser significamente más eficaz que la pública ni ha supuesto una mayor inversión a favor de los servicios públicos, denunciándose también el falseamiento de la competencia en las licitaciones públicas. Respecto a esto último, véase además WOLLMAN, H. (2013): "La experiencia de los ordenamientos europeos: ¿un «retorno» a las gestiones públicas/municipales?”, en Cuadernos de Derecho Local, QDL, núm. 31, pág. 75; y la nota de prensa de la Comisión Nacional de los Mercados y la Competencia (CNMC): "La CNMC sanciona con un total de 98,2 millones de euros a 39 empresas y tres asociaciones de gestión de residuos y saneamiento urbano", Madrid, 26 de enero de 2015.

9 Podemos ver ejemplos en las ciudades de Madrid y Barcelona, gobernadas por «Ahora Madrid» y «En Comú Podem», en relación con el servicio de bicicletas municipales y el agua, respectivamente. Consúltense "Carmena quiere remunicipalizar BiciMad a través de las cuentas de la EMT", en TeleMadrid, de 20 de noviembre de 2016; y Daniel Cordero Sánchez, "Colau apuesta por municipalizar el agua tras la anulación del contrato", en El País, de 18 de marzo de 2016. El contrato al que alude la segunda noticia fue el celebrado por el Área Metropolitana de Barcelona y SGAB (Agbar), propiedad de la francesa Suez, para prestar el servicio mediante una Sociedad de economía mixta. Acuerdo que fue posteriormente anulado por el TSJ de Cataluña (vid. nota 86).

10 Es de destacar el referéndum de 2011 celebrado en Italia acerca de la derogación de normas que facilitaban encomendar la gestión de los servicios públicos locales a operadores económicos privados en el que más del $95 \%$ del electorado votó a favor de dicha derogación. Consúltense los resultados en la web $h$ ttp://elezionistorico.interno.gov.it/index.php?tpel=F\&dtel=12/06/2011\&tpa=Y\&tpe=A \&lev0 $=0 \&$ levsut $0=0 \& e s 0=S \& m s=S$.

${ }^{11}$ Como paradigmas del éxito de la recuperación de la gestión pública se suelen mencionar las reinternacionalizaciones del abastecimiento del agua en las ciudades de Berlín, París y Grenoble.

12 Tornos Mas apunta que «el concepto de municipalización se vincula en sus orígenes de forma más directa a la idea de habilitar a los entes locales a realizar actividades de contenido económico. Estas actividades pueden tener además la naturaleza de servicios públicos si se trata de actividades de interés general que el ente local debe garantizar a sus ciudadanos». Vid. TORNOS MAS, J. (2017): "La remunicipalización de los servicios públicos locales", en FONT I LLOVET, T. y DÍEZ SÁNCHEZ, J. J. (coords.): Los servicios públicos locales. Remunicipalización y nivel óptimo de gestión: Actas del XXI Congreso de la Asociación Ítalo-Española de Profesores de Derecho administrativo, págs. 23-26.

13 Esta es la idea de municipalización que defiende TORNOS MAS, J. (2017): "La remunicipalización de los servicios públicos locales", cit., pág. 44, cuando dice que, con la municipalización, el ente local «asume de forma efectiva la garantía de la prestación, para lo cual podrá optar entre una forma de gestión directa o indirecta». En este mismo sentido, COLOMÉ I NIN, A. y GRAU I ARNAU, S. (2017): “«Remunicipalización» de servicios locales y competencia”, en Cuadernos de Derecho Local, QDL, núm. 43, pág. 128, quienes afirman que, «una vez municipalizado el servicio, el ente local deberá optar entre una forma de gestión directa (por él mismo) o indirecta, a través del encargo a operadores privados». 
REALA. Nueva Época - N.o 12, octubre-marzo 2019 - ISSN: 1989-8975 - DOI: 10.24965/reala.i12.10682 - [Págs. 72-96]

El procedimiento para la remunicipalización de servicios públicos. A propósito de los artículos 85 y $86 L R B R L$

Miguel León Acosta

riesgo de la Empresa mediante el poder de regularla y fiscalizar su régimen». Esta «tenderá a conseguir que la prestación de los servicios reporte a los usuarios condiciones más ventajosas que las que pudiera ofrecerles la iniciativa particular y la gestión indirecta». Así lo confirmó el Tribunal Supremo cuando concluyó que:

El protagonismo de la Administración en la actividad económica adopta diversos grados: Reglamentación intensiva de la actividad económica, declaración de servicio público, y empresa pública. La municipalización pertenece a este último grupo, porque la Administración asume el riesgo de ganancia o pérdida conviertiéndose en empresario ${ }^{14}$.

En efecto, de acuerdo con el artículo 45 RSCL, municipalización es la asunción de la gestión directa de un servicio público económico ${ }^{15}$ que hasta entonces estaba gestionado por un sujeto privado. Y, por tanto, remunicipalización es la asunción de la gestión directa de un servicio público económico que venía gestionándose por un privado y que, previamente, ya había sido gestionado directamente por la Corporación local ${ }^{16}$.

No son pocos los trabajos que, en los últimos años, se han escrito sobre el fenómeno de la remunicipalización ${ }^{17}$. En la mayoría de los casos, sin embargo, se han centrado sobre todo en cuestiones conceptuales y sustantivas, olvidando en buena medida la vertiente procedimental de dicho fenómeno. A ella, precisamente, se dedica el presente estudio, que analiza el procedimiento para el ejercicio de "actividades económicas» establecido en los artículos 86 de la Ley 7/1985, de 2 de abril, Reguladora de Bases del Régimen Local (en adelante, LRBRL) y 97 del Real Decreto Legislativo 781/1986, de 18 de abril, por el que se aprueba el texto refundido de las disposiciones legales vigentes en materia de Régimen Local (en adelante, TRRL) ${ }^{18}$. En particular, se estudiará si dicho procedimiento es de aplicación a la municipalización en sus dos acepciones: como procedimiento para asumir la prestación de un servicio público de contenido económico, indistintamente del modo de gestión, y como procedimiento para la asunción de su gestión directa. Seguidamente se analizarán también los requisitos que el artículo 85 LRBRL exige para optar por una u otra forma de gestión del servicio; cuestión estrechamente vinculada al procedimiento remunicipalizador antes aludido, según se verá.

\section{EL PROCEDIMIENTO DE LOS ARTÍCULOS 86 LRBRL Y 97 TRRL}

En este epígrafe se analizará, en primer lugar, el procedimiento recogido en el artículo 97 TRRL, que desarrolla lo establecido por el artículo 86 LRBRL. Dicho precepto establece, en primer lugar, el procedimiento general para el ejercicio de actividades económicas por parte del ente local en concurrencia con los privados

14 STS de 21 de julio de 1987 (rec. 628/1980), FJ 4. Los conceptos de empresa y empresario se deben interpretar de manera amplia abarcando no solo las formas empresariales de gestión directa, sino también aquellas otras que no tienen tal naturaleza, pues en todos los casos de gestión directa es el Municipio quien asume el riesgo empresarial entendido este como la exposición real a las incertidumbres del mercado.

15 Resulta importante recalcar que en este contexto el objeto de la municipalización son servicios públicos de carácter económico, que deberán tener «naturaleza mercantil, industrial, extractiva, forestal o agraria» [artículo 46.1 a) RSCL]. El régimen jurídico de la prestación de un servicio social es muy diverso al del servicio económico pues para prestar el primero mediante gestión directa «bastará el acuerdo de la Corporación en pleno» (artículo 42.1 RSCL). No obstante, distinguir estas categorías clásicas de servicio público económico y servicio público social puede resultar una tarea muy compleja en la práctica. Una misma actividad se podría calificar, de hecho, como uno u otro según cómo la Corporación local configure la misma. Vid. SÁNCHEZ DíAZ, J. L. (2003): "Los servicios locales de naturaleza económica. Municipalización, concesión y autorización”, en Revista de Estudios de la Administración Local y Autonómica, REALA, núm. 291, págs. 1.047-1.048; y ORTEGA BERNARDO, J. (2006): "Competencias, servicios públicos y actividad económica de los Municipios: (Presupuestos actuales para su delimitación y su ejercicio)”, cit., pág. 75.

16 Entre la doctrina, varios autores prefieren el término de «reinternalización» por entenderlo más correcto desde el punto de vista técnico-jurídico, al conceptuar la «municipalización» como prestación de un servicio público y no como la asunción de su gestión. En esta línea, García Rubio defiende que «algo que nunca dejó de ser municipal, pues siempre se ha prestado por el Municipio, difícilmente puede volver a serlo». Vid. GARCÍA RUBIO, F. (2017): "Pros y contras jurídico-administrativos de la «reinternalización» (remunicipalización) de servicios públicos", en FONT I LLOVET, T. y DÍEZ SÁNCHEZ, J. J. (coords.): Los servicios públicos locales. Remunicipalización y nivel óptimo de gestión: Actas del XXI Congreso de la Asociación Ítalo-Española de Profesores de Derecho administrativo, págs. 174-175; también TORNOS MAS, J. (2017): "La llamada remunicipalización de los servicios públicos locales. Algunas precisiones conceptuales", en Cuadernos de Derecho Local, QDL, núm. 43, págs. 24-25; y COLOMÉ I NIN, A. y GRAU I ARNAU, S. (2017): “«Remunicipalización» de servicios locales y competencia”, en Cuadernos de Derecho Local, QDL, cit., págs. $126-127$.

$17 \mathrm{Y}$ ello porque, pese al barniz ideológico que con frecuencia envuelve a este fenómeno, la remunicipalización es una cuestión también, y sobre todo, jurídica, como acertadamente afirma PONCE SOLÉ, J. (2016): "Remunicipalización y privatización de los servicios públicos y derecho a una buena administración. Análisis teórico y jurisprudencial del rescate de concesiones”, en Cuadernos de Derecho Local, QDL, núm. 40, págs. 70-73 y 101-103.

18 Se debe de tener en cuenta que este artículado constituye legislación básica, pudiéndose desarrollar por las Comunidades Autónomas en el ámbito de sus competencias, (DA 1. ${ }^{a}$ y ss. LRBRL y DF 7. ${ }^{a}$ TRRL). 
REALA. Nueva Época - N.o 12, octubre-marzo 2019 - ISSN: 1989-8975 - DOI: 10.24965/reala.i12.10682 - [Págs. 72-96]

El procedimiento para la remunicipalización de servicios públicos. A propósito de los artículos 85 y $86 L R B R L$

Miguel León Acosta

y, acto seguido, en el apartado segundo, añade unos trámites adicionales a dicho procedimiento para el caso de los servicios prestados en monopolio. Este procedimiento va dirigido a «acreditar la conveniencia y oportunidad de la medida» (artículo 86.1 LRBRL), es decir, de la iniciativa pública en la actividad económica (artículo 128 CE.2).

Una vez examinados los trámites que conforman este procedimiento pasaremos a cuestionarnos cuál es su ámbito objetivo, es decir, a qué actividades o servicios procede aplicar aquellos preceptos. En particular, analizaremos si la asunción de la prestación de un servicio público económico por una Entidad local -lo que buena parte de la doctrina denomina municipalización- entra dentro del ámbito de aplicación de la norma. Y, yendo aún más lejos, si el mero cambio de gestión del servicio está sometido o no a los trámites que aquí se expondrán. Cuestiones controvertidas y que han suscitado muchas dudas entre la doctrina debido a la escasa concreción de los artículos 86 LRBRL y 97 TRRL, que se refieren simplemente al desarrollo de «actividades económicas».

\section{Los trámites del procedimiento}

Como acaba de señalarse, es fundamentalmente el artículo 97 TRRL el que establece los distintos trámites procedimentales que deben seguirse para que una Corporación local pueda ejercer lo que el propio precepto denomina «actividades económicas», ya sea en concurrencia con otros privados o en monopolio.

Lo primero que llama la atención es que los trámites procedimentales que se establecen para el ejercicio de actividades económicas no son nuevos en nuestra historia de régimen local. En efecto, si se analiza la normativa anterior se observa cómo trámites prácticamente idénticos ya configuraban el procedimiento «municipalizador» que estableció en su artículo 171 el Estatuto Municipal de 8 de abril de 1924, primer texto normativo que reguló este tipo de procedimiento y al que le siguieron la Ley Municipal de 31 de octubre de 1935 y el posterior Decreto de 17 de junio de 1955 por el que se aprueba el Reglamento de Servicios de las Corporaciones locales ${ }^{19}$.

\subsection{Para el ejercicio de «actividades económicas» por las Entidades locales}

\section{A) Acuerdo inicial, previa designación de una Comisión de estudio}

El artículo 97 TRRL prevé, como primer trámite del procedimiento, «el acuerdo inicial, previa designación de una Comisión de estudio». Este acuerdo se adoptará por mayoría simple de los miembros presentes ${ }^{20}$. En cuanto a la Comisión de estudio, esta deberá estar compuesta por miembros de la Corporación y por personal técnico. No obstante, habrá que estar, además, a lo que establezca la respectiva legislación autonómica, como apunta Esteve Pardo ${ }^{21}$. Así lo ha entendido también la jurisprudencia, que ha anulado acuerdos una vez comprobado que la Comisión no cumplía con los requisitos de composición establecidos en la correspondiente normativa autonómica ${ }^{22}$. De la misma manera, cabría considerar la posibilidad de aplicar lo dispuesto por el artículo 56 RSCL, por ser desarrollo reglamentario del artículo 97 TRRL, y que reza:

Para la municipalización o provincialización de servicios se designará una Comisión especial, compuesta en la forma siguiente:

19 Sobre el procedimiento municipalizador del Estatuto Municipal de 1924 y de la Ley Municipal de 1935 véase MAGALDI, N. (2012): Los orígenes de la municipalización de servicios en España: el tránsito del Estado liberal al Estado social a la luz de la municipalización de servicios públicos. Madrid: Instituto Nacional de Administración Pública INAP, págs. 431-464.

20 Artículo 47.1 LRBRL. La letra k) del apartado segundo requiere el voto favorable de la mayoría absoluta del número legal de miembros de las corporaciones en caso de municipalización o provincialización de actividades en régimen de monopolio. Contrario sensu, debemos entender que será suficiente mayoría simple, que es la regla general, cuando el servicio se preste en concurrencia con privados.

21 Vid. ESTEVE PARDO, J. (2017): "Perspectivas y cauces procedimentales de la remunicipalización de servicios”, en Revista de Administración Pública, núm. 202, pág. 323.

22 Así por ejemplo, la STSJ de Cataluña 1059/2007, de 28 de diciembre, (rec. 231/2004), FJ 7. El Ayuntamiento de Fogars de la Selva municipalizó en monopolio el servicio de abastecimiento domiciliario de agua. En su tramitación designó una Comisión de estudio compuesta por tres miembros de la Corporación y tres técnicos, cumpliendo con lo exigido por el artículo 97 TRRL, pero obviando lo establecido en el artículo 244 a) del Decreto Legislativo 2/2003, de 28 de abril, por el que se aprueba el Texto refundido de la Ley municipal y de régimen local de Cataluña y el artículo 183 del Decreto 179/1995, de 13 de junio, por el que se aprueba el Reglamento de obras, actividades y servicios de los entes locales (ROAS), los cuales exigen la participación (en la comisión) de representantes de los usuarios. Ello llevó al Tribunal a anular el acuerdo. 
1. ${ }^{\circ}$ Concejales o Diputados y técnicos de la Corporación en número igual a la mitad más uno de los miembros que hayan de componer la Comisión.

2. ${ }^{\circ} \quad$ Elementos técnicos en el número y con las calidades que se fijan en el artículo siguiente.

3. ${ }^{\circ}$ Dos representantes de los usuarios, designados por las Cámaras Oficiales correspondientes, si las hubiere.

Sin embargo, no lo entendió así el Tribunal Superior de Justicia de Castilla y León, que en su sentencia de 28 de diciembre de 2012 afirmó que «está claro que el artículo 97.1.a) trascrito ha derogado en cuanto a la composición de la Comisión los artículos 56 y 57 del Reglamento de Servicios de las Corporaciones Locales» ${ }^{23}$.

\section{B) Redacción de la memoria}

La memoria constituye el trámite central y, sin duda, esencial de todo el procedimiento lo que, en consecuencia, explica que sea la causa por la que más procedimientos para el ejercicio de actividades económicas se han recurrido ante los tribunales y más anulaciones de acuerdos ha conllevado. Es precisamente a través de la memoria, elaborada por la Comisión de estudio, donde debe acreditarse la «conveniencia y oportunidad de la medida» (artículo 86 LRBRL), lo que a su vez se concretará en la determinación de los «aspectos social, jurídico, técnico y financiero de la actividad económica de que se trate», como señala expresamente el mencionado artículo 97 TRRL.

En cuanto al aspecto social, la Entidad Local deberá acreditar la utilidad pública que la prestación del servicio reportará a los vecinos. Se trata del aspecto decisivo para determinar la conveniencia y oportunidad de la medida. A propósito de estos conceptos, «el margen de apreciación y de decisión municipal acerca de la concurrencia de los mismos es extremadamente amplio, muy cercano, podría decirse, a la discrecionalidad» ${ }^{24}$. Por ello, con el fin de acreditar suficientemente la decisión, deberán reflejarse los hechos concretos, expresados, a ser posible, con cifras y estadísticas. En palabras del Tribunal Superior de Justica de País Vasco, «la iniciativa, y el expediente que la sustenta, tendrán que poner de relieve, no ya situaciones y estados de cosas teóricos, sino la verdadera ventaja que los vecinos y la comunidad local va a experimentar en términos objetivos y contrastables como resultado de esa injerencia pública en el libre mercado» ${ }^{25}$.

Por último, el legislador también se preocupa por esta eventual injerencia en el mercado y exige que en el preceptivo análisis de mercado realizado al efecto se recojan «los posibles efectos sobre la concurrencia empresarial» (artículo 86.1 LRBRL in fine). Consecuentemente, habrá que realizar una ponderación entre la utilidad pública resultado del ejercicio de la actividad económica por parte de la Entidad local y el perjuicio que sobre los empresarios tenga esta ${ }^{26}$.

En lo que afecta al aspecto jurídico, el artículo 97.1 TRRL menciona específicamente dos elementos. El primero es la determinación de la gestión, que se erige como uno de los elementos más importantes del procedimiento, principal -por razones obvias-cuando hablamos de (re)municipalización. De la forma de gestión escogida dependerá en buena medida la conveniencia y oportunidad de la decisión del ente local. Por su

${ }^{23}$ STSJ de Castilla y León 2260/2012, de 28 de diciembre (rec. 1435/2010). A nuestro entender, resulta curiosa esta interpretación pues la función del reglamento es el desarrollo de la Ley, como así hace el RSCL cuando especifica los requisitos que tienen que reunir los técnicos que componen la Comisión, si bien es verdad que nada dice el TRRL sobre los representantes de los usuarios. En cualquier caso, la omisión de representantes de los usuarios no parece ir en línea con el principio constitucional de participación ciudadana (artículo 9.2 CE), que se plasma en el ámbito local en el artículo 69 LRBRL. Lamentablemente, el TS, cuando examinó el recurso a esta sentencia, no se pronunció sobre este extremo en la STS de 23 de febrero de 2015 (rec. 595/2013), por no ser este el objeto del recurso.

${ }^{24}$ FERNÁNDEZ FARRERES, G. (2007): “Artículo 86”, en REBOLLO PUIG, M. (dir.) e IZQUIERDO CARRASCO, M. (coord.): Comentarios a la Ley Reguladora de las Bases del Régimen Local, vol. II, pág. 2.308. Valencia: Tirant lo Blanch.

${ }^{25}$ STSJ de País Vasco 473/2014, de 27 de octubre (rec. 768/2013). La misma anuló, conforme al artículo 63.1 de la Ley 30/1992, el acuerdo de constitución de la Sociedad Blaia Servicios Funerarios Municipales de Irún, S. A. por considerar insuficientemente acreditada la conveniencia y oportunidad del acuerdo al basar estas en la simple situación monopolística de «Tanatorio del Bidasoa, S. A -TABISA-», sin «concluir razonada y concluyentemente que se promueve una iniciativa económicamente viable que vaya a redundar en un mejor y más asequible servicio para los demandantes locales del mismo». En la misma línea se pronunció con anterioridad el Tribunal Supremo en la Sentencia de 10 de octubre de 1989 (conocida como Iniciatives), FJ 4 a 8, en la que, al analizar la concurrencia de un interés público en la creación de la Sociedad Anónima municipal de Barcelona «Iniciativas, S. A.», se constata «la ambigüedad, inconcreción, vaguedad, generalidad, imprecisión...» del objeto de la empresa. Por ello, mantiene el Tribunal que «no queda acreditada ni justificada de ningún modo la oportunidad o conveniencia» de la creación de la empresa.

${ }^{26}$ De esta opinión son COLOMÉ I NIN, A. y GRAU I ARNAU, S. (2017): "«Remunicipalización» de servicios locales y competencia”, en Cuadernos de Derecho Local, QDL, núm. 43, cit., págs. 147 y 156, quienes abogan por que «el ente local debería llevar un análisis del impacto competitivo de su decisión basado en los principios de necesidad, proporcionalidad y mínima distorsión». 
REALA. Nueva Época - N.o 12, octubre-marzo 2019 - ISSN: 1989-8975 - DOI: 10.24965/reala.i12.10682 - [Págs. 72-96]

El procedimiento para la remunicipalización de servicios públicos. A propósito de los artículos 85 y $86 L R B R L$

Miguel León Acosta

relevancia en el procedimiento, se le ha dedicado un epígrafe aparte. Por otro lado, se exige la concreción de los casos en que debe cesar la prestación de la actividad ${ }^{27}$.

Con referencia al aspecto técnico, el expediente deberá contener todas las especificaciones necesarias para llevar a cabo la actividad. En este sentido, el RSCL exige un «anteproyecto de obras para la implantación del servicio, si este las requiriere, o bases de su planteamiento técnico, con el detalle suficiente para formar idea de la instalación o actividad de que se tratare» (artículo 61.1. $\left.{ }^{\circ} \mathrm{RSCL}\right)^{28}$.

Finalmente, son dos los aspectos que debemos destacar en relación con el elemento financiero que debe contener toda memoria. En primer lugar, la Ley Orgánica 2/2012, de 27 de abril, de Estabilidad Presupuestaria y Sostenibilidad Financiera (LOEPSF) y la complementaria Ley 27/2013, de 27 de diciembre, de racionalización y sostenibilidad de la Administración Local (LRSAL), que desarrollan el mandato del artículo $135 \mathrm{CE}$ relativo al principio constitucional de estabilidad presupuestaria, centran su preocupación, precisamente en esta $y$ en la sostenibilidad financiera ${ }^{29}$. Consecuentemente, la LRSAL modifica la LRBRL, impregnándola de este principio. En concreto, se modifica el artículo 86.1, que queda redactado de la siguiente forma:

Las Entidades Locales podrán ejercer la iniciativa pública para el desarrollo de actividades económicas, siempre que esté garantizado el cumplimiento del objetivo de estabilidad presupuestaria y de la sostenibilidad financiera del ejercicio de sus competencias. En el expediente acreditativo de la conveniencia y oportunidad de la medida habrá de justificarse que la iniciativa no genera riesgo para la sostenibilidad financiera del conjunto de la Hacienda municipal debiendo contener un análisis del mercado, relativo a la oferta y a la demanda existente, a la rentabilidad y a los posibles efectos de la actividad local sobre la concurrencia empresarial ${ }^{30}$.

La estabilidad presupuestaria y la sostenibilidad financiera se configuran de esta manera como requisito indispensable para el ejercicio de una actividad económica, debiéndose realizar un análisis de mercado en el que se compruebe la ausencia de riesgo para la estabilidad y sostenibilidad de la Corporación. A este respecto, entendemos que este riesgo deberá valorarse por los tribunales, quienes lo deberán poner en relación con el interés general de la medida y ponderar ambos. En cualquier caso, todo hace prever -dado el alto nivel de exigencia mostrado en otros aspectos del procedimiento- que los tribunales también serán rigurosos cuando deban enjuiciar este requisito.

En segundo lugar, el legislador también especifica la necesidad de que a la memoria se le acompañe de un «proyecto de precios». Este será también pieza clave tanto para resolver sobre la conveniencia y oportunidad de la medida en su aspecto social (unos precios más bajos serían beneficiosos para los vecinos), como para resolver sobre la estabilidad presupuestaria y sostenibilidad financiera por motivos evidentes. El artículo aclara que «para la fijación de precios se tendrá en cuenta que es lícita la obtención de beneficios aplicable a las necesidades generales de la Entidad local como ingreso de su Presupuesto, sin perjuicio de la constitución de fondos de reserva y amortizaciones» ${ }^{31}$. La formulación de este inciso final nos hace pensar que el legislador no prevé como fin principal de la actividad económica la mera recaudación, aunque sí la admite como una consecuencia «lícita» de la actividad ${ }^{32}$.

27 Así por ejemplo, el artículo 103.2 TRRL establece que «cuando las pérdidas excedan de la mitad del capital social, será obligatoria la disolución de la Sociedad». Una vez producida esta, como es lógico, «la Corporación resolverá sobre la continuidad y forma de prestación del servicio».

${ }_{28}$ Con referencia a la importancia de este anteproyecto de obras se pronunció el Tribunal Superior de Justicia de Baleares en su Sentencia 957/2010, 29 de octubre (rec. 422/2005), FJ 3, en relación a la creación de la Entidad pública empresarial «Funeraria Municipal de Sóller», en la que el Tribunal considera indispensable en este caso el anteproyecto, por las características del servicio, para valorar la oportunidad y conveniencia del proyecto.

29 En esta lógica, es natural acudir en primer lugar a la LOEPSF para saber qué debemos entender por ambos conceptos. En concreto, su artículo 3.2 define «estabilidad presupuestaria» como «la situación de equilibrio o superávit estructural». Por su parte, el artículo 4.2 establece que «se entenderá por sostenibilidad financiera la capacidad para financiar compromisos de gasto presentes y futuros dentro de los límites de déficit, deuda pública y morosidad de deuda comercial conforme a lo establecido en esta Ley, la normativa sobre morosidad y en la normativa europea».

${ }^{30}$ Lo señalado en cursiva corresponde a lo añadido por la reforma efectuada por la LRSAL.

31 En esta línea, el Real Decreto Legislativo 2/2004, de 5 de marzo, por el que se aprueba el texto refundido de la Ley Reguladora de las Haciendas Locales (en adelante, $L R H L$ ) no solo prevé la obtención de beneficios sino que establece que «el importe de los precios públicos deberá cubrir como mínimo el coste del servicio prestado o de la actividad realizada», pudiéndose fijar por debajo de este límite únicamente «cuando existan razones sociales, benéficas, culturales o de interés público que así lo aconsejen» (artículo 44).

32 Sobre la licitud de la obtención de beneficios económicos en la prestación de servicios públicos locales se ha discutido desde antiguo. Cfr. MAGALDI, N. (2012): Los orígenes de la municipalización de servicios en España: el tránsito del Estado liberal al Estado social a la luz de la municipalización de servicios públicos, cit., págs. 338-343. 
Por último, no está de más destacar que, en palabras del Tribunal Supremo, «la naturaleza y la finalidad de dicho expediente lo convierten en presupuesto procedimental esencial para legitimar la inmisión del poder público en la actividad económica privada, tal como aparece configurado en la Ley de acuerdo con los principios constitucionales. Por ello, (...) la ausencia de expediente previo implica la nulidad de pleno derecho» ${ }^{33}$.

\section{C) Exposición pública de la memoria}

Una vez redactada la Memoria por la Comisión de estudio, y de que esta «sea tomada en consideración por la Corporación», se abrirá un trámite de exposición pública «por plazo no inferior a treinta días naturales, durante los cuales podrán formular observaciones los particulares y Entidades».

La jurisprudencia ha entendido que se trata de un trámite esencial, cuya omisión frustra los derechos de los ciudadanos particulares y entidades sociales vedándoseles la oportunidad de conocer la Memoria y participar en el «proceso deliberativo» ${ }^{34}$, por lo que tiene como consecuencia jurídica la anulabilidad del acto conforme el actual artículo 48.2 de la Ley 39/2015 del Procedimiento Administrativo Común de las Administraciones públicas (en adelante, LPACAP). La exposición de la memoria se configura de esta manera como una vía de participación ciudadana, en concordancia con el mandato constitucional del artículo 9.2 y que el legislador recoge, para el ámbito local, en el artículo 69 LRBRL.

Por lo que se refiere a la vía de exposición pública que debe emplear la Administración, la jurisprudencia mantiene que será suficiente, dado su ámbito local, la publicación de la Memoria en el Boletín Oficial de la Provincia (BOP) y el Boletín Oficial de la Comunidad Autónoma correspondiente ${ }^{35}$.

\section{D) Aprobación final del proyecto}

Transcurrido el plazo previsto de exposición pública y habiendo tenido en cuenta las alegaciones hechas, se procederá a la aprobación final por el Pleno del Ayuntamiento que, en ausencia de mención expresa por el artículo 97 TRRL y al igual que ocurría con el acuerdo inicial, será por mayoría simple (art. 47 LRBRL).

\subsection{Para el ejercicio de «actividades económicas» en régimen de monopolio}

En concordancia con el Derecho de la Unión Europea y, en particular el artículo 106.2 del Tratado de Funcionamiento de la Unión Europea (en adelante, TFUE), los servicios públicos que tengan un contenido económico serán prestados con pleno respeto a las normas de la competencia y en concurrencia con los sujetos privados. No obstante, cabe la existencia de razones que justifiquen establecer restricciones a la competencia $\mathrm{o}$, incluso, extraer toda competencia de otros operadores económicos ${ }^{36}$. Partiendo de esta

${ }_{33}$ STS de 1 de febrero de 2002 (rec. 6139/1996), FJ 5. Se discutía en esta sobre la legalidad de la creación de una sociedad municipal para hacerse cargo del servicio de recogida de basuras y limpieza viaria sin haber seguido para dicha creación el expediente del artículo 97.1 TRRL y, por tanto, se declaró nulo el acuerdo por el que se implantaba el servicio a través de esta sociedad.

34 STSJ de Canarias 114/2009, de 15 de septiembre (rec. 96/2009), FJ 3. En el presente caso, el Ayuntamiento de Santa Cruz de Tenerife realizó un cambio de gestión de los servicios públicos municipales relacionados con el ciclo integral del agua, que venía prestando de forma directa la sociedad de capital íntegramente municipal denominada «Empresa Municipal de Aguas de Santa Cruz de Tenerife» (EMMASA), para establecer el modo de gestión indirecta a través de una Sociedad de economía mixta, de tal manera que EMMASA pasaba a integrarse en una sociedad de esta naturaleza mediante la venta a terceros de 212 acciones del total de 224 en que se hallaba dividido su capital social y reservándose solo 12 acciones. Esta venta de casi la totalidad de la sociedad municipal, previa al concurso para la adjudicación del contrato, equivalía, según el Tribunal, al ejercicio de una actividad económica y, por ende, al no contemplarse la exposición pública de la memoria [artículo 97.1 c) TRRL], debía declarar nulo el acuerdo. Esta sentencia fue confirmada por la STS de 20 de noviembre de 2012 (rec. 80/2009).

${ }^{35}$ STSJ de Castilla y León 2260/2012, de 28 de diciembre, FJ 5. El objeto de la controversia versó sobre la legalidad del cambio de gestión del servicio de abastecimiento domiciliario de agua potable del Municipio de León que ejercía directamente el Ayuntamiento a través del Servicio Municipalizado de Aguas, órgano especial de administración, para prestarse posteriormente mediante gestión indirecta a través de una Sociedad de economía mixta. En lo que aquí importa, la obligación de la publicación del trámite de información pública de la memoria en el BOE (artículo 63.1 RSCL) después de la entrada en vigor de la LRBRL se debe entender referida a la publicación en el Boletín Oficial de la Comunidad Autónoma.

${ }_{36}$ En esta línea, véanse COLOMÉ I NIN, A. y GRAU I ARNAU, S. (2017): “«Remunicipalización» de servicios locales y competencia”, cit., págs. 132-134; ORTEGA BERNARDO, J. y DE SANDE PÉREZ-BEDMAR, M. (2015): "El debate sobre la remunicipalización de los servicios públicos: aspectos jurídicos, administrativos y laborales", cit., págs. 63-64; y la AUTORIDAD CATALANA DE LA COMPETENCIA en su informe sobre el caso Santa Maria d'Oló (OB 19/2015), pág. 6. 
REALA. Nueva Época - N.o 12, octubre-marzo 2019 - ISSN: 1989-8975 - DOI: 10.24965/reala.i12.10682 - [Págs. 72-96]

El procedimiento para la remunicipalización de servicios públicos. A propósito de los artículos 85 y 86 LRBRL

Miguel León Acosta

idea, el legislador declara en el artículo 86.2 LRBRL, en desarrollo del artículo 128.2 CE, la reserva en favor de ciertos servicios (servicios esenciales) ${ }^{37}$ con la que se posibilita la exclusión de la competencia.

Respecto a esta reserva, la doctrina ${ }^{38}$ y la jurisprudencia ${ }^{39}$ recuerdan que no opera de forma automática, sino que se deben distinguir al menos dos fases: primero, la habilitación legal, mediante el artículo 86.2 o ley sectorial; y, segundo, la declaración de voluntad de la Entidad Local haciendo efectiva la reserva, a través del procedimiento del artículo 97.2 TRRL, que se configura como un procedimiento «agravado» en el que, a los trámites examinados en el apartado inmediatamente anterior, se añaden otros complementarios. Veamos cuáles son.

\section{A) Informe de la autoridad de competencia correspondiente}

Este trámite ha sido una de las tantas novedades introducidas por la LRSAL. Sirviéndonos del estudio de los informes de estas autoridades realizado por Esteve Pardo, podemos afirmar que, en estos primeros años de vigencia de la norma, estas se han mostrado muy exigentes respecto a la necesidad de justificar detalladamente la conveniencia del monopolio y de la forma de gestión elegida, en línea con lo mantenido por la jurisprudencia en relación con la conveniencia y oportunidad de la medida ${ }^{40}$. Respecto a la forma de gestión, se observa una clara preferencia de las diferentes autoridades de la competencia por la gestión indirecta. Si bien la prestación en régimen de monopolio supone per se una eliminación de la concurrencia empresarial, con la gestión indirecta todavía puede existir cierta competencia. En efecto, el Consejo de Defensa de la Competencia de Andalucía argumenta que con la gestión indirecta «los candidatos establecerán una suerte de competencia entre ellos para resultar finalmente elegidos, lo que a su vez debería producir un aumento en la eficiencia en la prestación del servicio " ${ }^{41}$. Es decir, se mantiene una competencia por el mercado, a pesar de haber eliminado la competencia en el mercado.

En todo caso, es conveniente señalar que este informe -que se emitará en el plazo de diez días (artículo 80.2 LPACAP)- será preceptivo, pero no vinculante, de acuerdo al artículo 80.1 LPACAP. Por tanto, la Corporación local podrá actuar en sentido contrario a lo aconsejado en el informe ${ }^{42}$.

\section{B) Acuerdos de la Corporación Local}

Según el artículo 47.2.k) LRBRL, los acuerdos relativos a la municipalización o provincialización de actividades en régimen de monopolio requerirán el voto favorable de la mayoría absoluta del número legal de miembros de la Corporación. Así pues, tanto el acuerdo que da inicio al expediente, como el acuerdo que le pone fin una vez redactada y publicada la Memoria y habiéndose emitido el informe de la autoridad correspondiente, deberán ser aprobados por mayoría absoluta y no por mayoría simple como en el caso

37 «El abastecimiento domiciliario y depuración de aguas; la recogida, tratamiento y aprovechamiento de residuos, y el transporte público de viajeros» así como los que establezcan, mediante Ley, el Estado y las Comunidades Autónomas. Así, por ejemplo, el legislador andaluz efectuó idéntica reserva para los servicios de alumbrado público; limpieza viaria; y prevención y extinción de incendios [artículos 32.1 LAULA y 92.2 d) del Estatuto de Autonomía de Andalucía].

38 Vid. TORNOS MAS, J. (2017): "La remunicipalización de los servicios públicos locales”, cit., pág. 44; ORTEGA BERNARDO, J. (2006): "Competencias, servicios públicos y actividad económica de los Municipios: (Presupuestos actuales para su delimitación y su ejercicio)", cit., pág. 67; y ESTEVE PARDO, J. (2017): "Perspectivas y cauces procedimentales de la remunicipalización de servicios", cit., págs. 319-321, entre otros.

39 Vid. STS de 21 de diciembre de 2000 (rec. 6448/1996), FJ 6; y la STSJ de Galicia 1724/2005, de 25 de noviembre (rec. 7359/2003), FJ 8.

40 Tanto el informe de la Autoridad Catalana de la Competencia sobre el caso de Santa Maria d’Oló (OB 19/2015), pág. 6, como el del Consejo de Defensa de la Competencia de Andalucía de 20 de enero de 2009, págs. 4-5, consideran insuficientes las justificaciones dadas por la Corporación. En el primer caso, en relación a la municipalización del servicio del agua del Municipio de Santa Maria d'Oló a través de una sociedad anónima municipal, Aigües de Manresa, S. A., propiedad del Ayuntamiento de Manresa, mediante un convenio de colaboración entre ambos Municipios. El segundo caso, relativo a la prestación del servicio de gestión integral del ciclo del agua en el Municipio de Nerja, en régimen de monopolio y mediante gestión indirecta a través de la creación de una Sociedad de economía mixta.

41 Informe del Consejo de Defensa de la Competencia de Andalucía de 20 de enero de 2009, pág. 3. En la misma línea la Autoridad Catalana de Competencia, Informe de Santa Maria d'Oló, (OB 19/2015), pág. 8, advierte que «el uso sistemático de este instrumento de gestión directa puede llegar a provocar una posible pérdida de eficiencia derivada de la ausencia de tensión competitiva a la hora de fijar las condiciones de ejecución del encargo de gestión».

42 No obstante, en el caso de que la Administración se separe del criterio indicado por el órgano consultivo -en este caso el órgano de la competencia-, aquella deberá motivar explícitamente la actuación en el sentido contrario al aconsejado [artículo 35.1 c) LPACAP]. Vid. ALEMANY GARCÍAS, J. (2018): La recuperación de los servicios públicos locales. Madrid: Civitas Thomson Reuters, págs. 157-159. 
REALA. Nueva Época - N.o 12, octubre-marzo 2019 - ISSN: 1989-8975 - DOI: 10.24965/reala.i12.10682 - [Págs. 72-96]

El procedimiento para la remunicipalización de servicios públicos. A propósito de los artículos 85 y 86 LRBRL

Miguel León Acosta

de la realización de actividades económicas en concurrencia con el mercado. La exigencia de este mayor consenso se explica por la mayor injerencia de la medida sobre el mercado.

\section{C) Elevación del expediente al órgano competente de la Comunidad Autónoma}

La propia Constitución reconoce la autonomía de los Municipios (artículos 137 y 140 CE) y de los demás entes locales, que «deberán disponer de los medios suficientes para el desempeño que la ley atribuye a las Corporaciones respectivas» (artículo $142 \mathrm{CE}$ ). Por lo tanto, no caben, por parte de las Administraciones autonómicas ni de la Administración General del Estado, controles de oportunidad sobre las decisiones de las Administraciones Locales en el ámbito de sus competencias. Así las cosas, la elevación del expediente no tendrá otro fin que el de llevar a cabo un control de legalidad ${ }^{43}$. El órgano competente deberá valorar si el acuerdo invade competencias legalmente atribuidas a la Comunidad Autónoma de que se trate, para lo que dispondrá de un plazo de tres meses. Para resolver sobre el mismo podrá solicitar «dictamen del Consejo de Estado o del órgano consultivo superior del Consejo de Gobierno de la Comunidad Autónoma, donde existiese, en cuyo caso no se computará el tiempo invertido en evacuar la consulta» ${ }^{44}$.

\section{Sobre la aplicación de los artículos 86 LRBRL y 97 TRRL a la actividad económica de las Entidades Locales}

De la lectura de los artículos 86 LRBRL y 97 TRRL, así como de cuanto se ha dicho en el epígrafe anterior, es posible extraer, de entrada, dos conclusiones respecto al ámbito de aplicación de aquellos. En primer lugar, si la Administración (local) decide emprender una actividad económica en sentido estricto, esto es, una actividad cuya prestación no responde a la satisfacción de una necesidad colectiva básica ${ }^{45}$, deberá justificar la utilidad pública que esta genera, siguiendo el procedimiento descrito en el epígrafe anterior relativo a la iniciativa pública para actividades económicas. En segundo lugar, si la actividad que pretende desarrollar es la de un servicio público en régimen de monopolio, deberá seguir el procedimiento agravado de los artículos 86.2 LRBRL y 97.2 TRRL, al que también hemos aludido.

Partiendo de estas premisas -que no se discuten ni por la jurisprudencia ni por la doctrina-, surgen dudas en torno a la aplicación del procedimiento estudiado en dos situaciones determinadas: a) el ejercicio de una actividad calificada como servicio público y prestada en concurrencia con los particulares, y b) el cambio de gestión del servicio que se venía prestando con anterioridad.

${ }^{43}$ En este sentido, ESTEVE PARDO, J. (2017): "Perspectivas y cauces procedimentales de la remunicipalización de servicios", cit., pág. 328 y ORTEGA BERNARDO, J. (2006): "Competencias, servicios públicos y actividad económica de los Municipios: (Presupuestos actuales para su delimitación y su ejercicio)", cit., págs. 70-71; confirmándolo también la STC 4/1981, de 2 de febrero, FJ 3.

44 Dictamen que será, sin perjuicio de la normativa de los órganos consultivos autónomicos, no vinculante de acuerdo al artículo 2.2 Ley Orgánica 3/1980, de 22 de abril, del Consejo de Estado.

${ }_{45}$ Me refiero aquí a lo que el profesor Villar Palasí denominó dación de bienes y servicios al mercado, como categoría diferenciada de la de los servicios públicos. Vid. VILLAR PALASÍ, J. L. (1950): "La actividad industrial del Estado en el Derecho Administrativo", en Revista de Administración Pública, núm. 3, págs. 60-61. Hoy se suele hablar más bien de iniciativa pública económica o de gestión económica. Vid. EZQUERRA HUERVA, A. (2017): "Sobre el procedimiento administrativo a seguir para la remunicipalización de servicios", en Diario La Ley, núm. 8.982, pág. 5. No obstante, las categorías de servicio público (económico) y actividad económica en sentido estricto no son fáciles de delimitar en la práctica. Podríamos preguntarnos, por ejemplo, si unas clases de aerobic o de fitness pueden llegar a considerarse servicio público, cuestión que ya se le planteó al Tribunal Supremo, SSTS de 20 de junio de 2006 (rec. 9108/2003); y de 14 de febrero de 2007 (rec. 2621/2004). En ambos casos, la Asociación Aprodeport exigió el cese de los servicios ofertados (clases de aerobic y fitness) por los Ayuntamientos de Burriana y Villareal, respectivamente, por ser contrarios a la libertad de empresa (artículo $38 \mathrm{CE}$ ). Para resolver este tipo de controversias los tribunales suelen acudir a las actividades y competencias recogidas en los artículos 25 y 26 LRBRL; toda actividad que se encuentra comprendida en estos artículos es calificada, normalmente, como servicio público. Vid. SSTS de 1 de febrero de 2002 (rec. 6139/1996), FJ 2, y de 4 de julio de 2003 (rec. 8954/1997), FJ 1, y los Tribunales Superiores de Justicia, STSJ de Canarias 114/2009, de 15 de septiembre (rec. 96/2009), FJ 1 y 2; y STSJ de Castilla y León 2260/2012, de 28 de diciembre (rec. 1435/2010), FJ 4. Partiendo de este razonamiento, el Tribunal Supremo en las SSTS de 20 de junio de 2006 , FJ 5 y 6 ; y de 14 de febrero de 2007, mencionadas arriba, desestimó la pretensión de la Asociación Aprodeport, entendiendo que era suficiente que una ley (la Ley valenciana del Deporte) hubiera declarado que el deporte, y las instalaciones asociadas al mismo, constituían un servicio público, FJ 7 y 9 . No obstante, en vista de esta tendencia jurisprudencial, parece necesario recordar que las categorías «competencia» y «servicio público» no son siempre coincidentes. No basta con que una actividad de competencia local satisfaga un interés general -pues es requisito común e indispensable de toda actividad administrativa (artículo 103.1 CE)-, sino que debe responder a una necesidad pública, concepto más intenso que el «simple» interés general. Vid. ARANA GARCÍA, E. (1997): Las sociedades municipales de gestión urbanística. Madrid: Marcial Pons, págs. 55-57 y 112-115. 


\subsection{La aplicación del procedimiento de los artículos 86 LRBRL y 97 TRRL a la asunción de servicios públicos por parte de la Corporación Local}

La cuestión que debemos plantearnos ahora es si resulta necesario llevar a cabo el procedimiento relativo al ejercicio de actividades económicas (artículo 97.1 TRRL), cuando la actividad en cuestión sea un servicio público de contenido económico. Un sector doctrinal en el que destaca Ortega Bernardo, amparándose en la normativa europea en materia de servicios de interés económico general, entiende que la distinción relevante radica en «la diferencia entre la referida iniciativa pública económica local (sometida a las normas de la competencia) y los servicios públicos (reservados o no)» siendo objeto de aplicación de los artículos referidos únicamente las primeras actividades ${ }^{46}$. Esta posición fue acogida por el TS ya en una sentencia de $1997^{47}$, y ha sido reiterada recientemente por los Tribunales Superiores de Justicia de Andalucía ${ }^{48}$ y de Castilla y León ${ }^{49}$. Respecto de este último, merece la pena transcribir la argumentación utilizada en tanto que hace suyo el razonamiento de la profesora Ortega Bernardo ${ }^{50}$.

En el marco jurídico actual integrado con la normativa europea, la diferencia fundamental se encuentra entre la iniciativa pública económica local, sometida a las normas de la competencia, y los servicios públicos (reservados o no) que, si no se reservan, se pueden prestar en concurrencia con la actividad empresarial privada, pero no necesariamente en competencia con ella (sic.) (en expresión de la profesora Ortega Bernardo), trasladando la distinción del derecho europeo entre la actividad empresarial (pública o privada) sometida al cumplimiento de las normas de la competencia (art. 106.1 del TFUE) y la que no está sometida a estas normas de competencia, que son la excepción y tienen cobertura también en el art. 106.2 del TFUE. Lo fundamental es que la ley declare la actividad como servicio público o competencia municipal, como es el caso del abastecimiento y depuración de aguas, porque esta declaración puede comportar debido al interés público prevalente el quedar exonerado de las normas de defensa de la competencia por aplicación de la excepción del art. 4 de la Ley 15/2007, de 3 de julio, de Defensa de la Competencia (...).

Dicha jurisprudencia, por lo tanto, excluye del ámbito del artículo 86 LRBRL la prestación de un servicio público para situarla en el ámbito de la potestad autoorganizativa del artículo 85 LRBRL, reservándose el artículo 86 para la mera actividad empresarial del ente local.

En realidad, la controversia se suscita en buena medida por la falta de concreción del ámbito objetivo de aplicación de la norma, pues al hablar el artículo 86 LRBRL de «actividades económicas» permite entender tanto que se refiere solo a la mera actividad empresarial de la Administración como, por el contrario, que abarca cualquier actividad o servicio que tenga un contenido económico, incluyendo por lo tanto también servicios públicos. Pensamos que una forma razonable de abordar esta compleja cuestión -que no puede

46 ORTEGA BERNARDO, J. y DE SANDE PÉREZ-BEDMAR, M. (2015): "El debate sobre la remunicipalización de los servicios públicos: aspectos jurídicos, administrativos y laborales", cit., pág. 71.

47 STS de 23 de mayo de 1997 (rec. 6813/1991), FJ 5. El Ayuntamiento de Los Silos interesaba la nulidad de las resoluciones del Cabildo de Tenerife por las que se aprueba la gestión directa de la Balsa de la Montaña de Taco para el abastecimiento de agua para el riego. Ello sin seguir los trámites fijados en el artículo 97 TRRL. El Tribunal falló a favor de la legalidad de los acuerdos al entender que, tratándose de un servicio público, no debía de seguir los tramites del mencionado artículo que quedaría reservado a la «actividad industrial o comercial distinta de los servicios públicos locales» para la que "además del título habilitante se exige, por la trascendencia de la medida, un reforzamiento de las formalidades del expediente administrativo en los términos del invocado artículo 97 TRRL», recalcando que, por el contrario, no ocurre lo mismo con «los servicios públicos de la competencia de los Entes Locales».

48 SSTSJ de Andalucía 355/2017, de 3 de abril (rec. 464/2016), y 362/2017, de 30 de marzo (rec. 642/2016). Ambas sentencias versan sobre la adquisición en 2009, por parte del Ayuntamiento de Almonte, de la sociedad Exclusivas Doñana, S. L., titular y gestora del campo de golf de Matalascañas. El Tribunal entendió que la gestión de este campo de golf, entre otros motivos por ser el único de la zona, constituía un servicio público de carácter obligatorio al ser una instalación deportiva de acuerdo con el artículo 26 LRBRL. Como consecuencia, no le eran de aplicación los artículos 86.1 LRBRL y 97.1 TRRL, declarando ajustado a derecho el acuerdo de adquisición del campo de golf como «servicio público turístico-deportivo».

49 STSJ de Castilla y León 1241/2017, de 3 de octubre (rec. 360/2017), FJ 5. La sociedad Aguas de Valladolid recurre el auto del Juzgado de lo Contencioso-administrativo que deniega las medidas cautelares solicitadas en relación al acuerdo para el cambio de gestión del abastecimiento de aguas del Ayuntamiento de Valladolid, de una gestión indirecta mediante la empresa concesionaria Sociedad de Aguas de Valladolid a una gestión directa mediante la creación de una Entidad pública empresarial local. Uno de los motivos esgrimidos -y rechazados- fue no haber seguido el procedimiento de los artículos 86 LRBRL y 97 TRRL.

50 Vid. Julia ORTEGA BERNARDO, J. y DE SANDE PÉREZ-BEDMAR, M. "El debate sobre la remunicipalización de los servicios públicos", cit., pág. 71. 
REALA. Nueva Época - N.o 12, octubre-marzo 2019 - ISSN: 1989-8975 - DOI: 10.24965/reala.i12.10682 - [Págs. 72-96]

El procedimiento para la remunicipalización de servicios públicos. A propósito de los artículos 85 y $86 L R B R L$

Miguel León Acosta

resolverse desde la literalidad del precepto- es analizarla desde los demás criterios interpretativos que se desprenden del artículo 3.1 del Código Civil, particularmente desde los criterios sistemático y teleológico.

\section{A) Criterio sistemático}

Atendiendo al contexto normativo, el profesor Ezquerra Huerva ${ }^{51}$ apunta diferentes normas que pueden ser de utilidad para el debate. Así, en primer lugar, llama la atención sobre la propia estructura de los artículos 86 LRBRL y 97 TRRL, que describen el procedimiento a seguir cuando la Entidad local pretende realizar "una actividad económica» en concurrencia con los privados. En segundo lugar, se añaden unos requisitos a dicho procedimiento en el caso de que se quieran prestar en régimen de monopolio ciertos servicios (públicos) que la ley califica como esenciales. Así las cosas, parece que el legislador configura los trámites de dichos artículos como un único procedimiento que se agrava para el caso de servicios prestados en monopolio. Según este razonamiento, es plausible pensar que cualquier servicio público de contenido económico, aunque no se preste con exclusión de la iniciativa privada sino en concurrencia, deberá someterse al procedimiento referido.

En segundo lugar, es necesario mencionar el artículo 95.1 TRRL que parece bastante clarificador respecto a la cuestión discutida. Este dispone que «los servicios públicos locales, incluso los ejercidos en virtud de la iniciativa pública prevista en el artículo 86 de la Ley 7/1985, de 2 de abril, podrán ser gestionados directa o indirectamente». Esta norma encuadra a ciertos servicios públicos locales dentro de la iniciativa pública del artículo 86 LRBRL. Entendemos que el legislador se refiere a aquellos servicios públicos de carácter económico o, más concretamente, que puedan afectar a la competencia.

En tercer lugar, es importante mencionar el apartado 5 de la Disposición adicional tercera de la Ley 9/2017, de 8 de noviembre, de Contratos del Sector Público, por la que se transponen al ordenamiento jurídico español las Directivas del Parlamento Europeo y del Consejo 2014/23/UE y 2014/24/UE, de 26 de febrero de 2014 (en adelante, LCSP). Este dice expresamente que, en los contratos de concesión de obras y de servicios, el expediente del artículo 86.1 LRBRL se tramitará conjuntamente con el estudio de viabilidad regulado en la Ley de Contratos del Sector Público. Siendo el contrato de concesión el lógico heredero del extinto contrato de gestión de servicios públicos ${ }^{52}$, todo hace pensar, en línea con lo antes expuesto, que el legislador da por sentado la obligación de seguir el procedimiento del artículo 86 LRBRL cuando se prestan servicios públicos.

Por último, interesa también en esta sede rechazar los argumentos anteriormente señalados por Ortega Bernardo y la jurisprudencia de los Tribunales Superiores de Andalucía y Castilla León en relación con la no aplicación de los artículos 86.1 LRBRL y 97.1 TRRL cuando se trata de un servicio público. A diferencia de lo que se indica en la sentencia mencionada, la interpretación del artículo 106 TFUE no nos lleva necesariamente a afirmar la exclusión de aquel procedimiento en el supuesto de que se quiera establecer un servicio público local en concurrencia con los privados.

Y ello porque del artículo 106 TFUE no se pueden extraer dos figuras totalmente opuestas, sujetas a regímenes jurídicos distintos, como son las actividades económicas en sentido estricto y los servicios de interés económico general. De hecho, lo que hace el apartado segundo de dicho precepto es remarcar la necesidad de acatar las normas de la competencia, también cuando se tratan de servicios de interés económico general ${ }^{53}$. Es decir, ambas actividades están sujetas al mismo régimen jurídico, con la salvedad de los casos en los que, tratándose de un servicio de interés económico general, la aplicación de las normas de la competencia «impida, de hecho o de derecho, el cumplimiento de la misión específica confiada» ${ }^{54}$.

51 EZQUERRA HUERVA, A. (2017): "Sobre el procedimiento administrativo a seguir para la remunicipalización de servicios", cit., págs. 7-9

${ }^{52}$ Así se deduce de la Disposición adicional trigésima cuarta de la LCSP, como bien apunta GOSÁLBEZ PEQUEÑO, H. (2018): "Potestad autoorganizativa, cooperación administrativa y servicios públicos locales", en MELLADO RUIZ, L. y FORNIELES GIL, Á. (coords.): Gestión cooperativa en el ámbito local, pág. 188. Valencia: Tirant lo Blanch.

53 Estas normas de la competencia deben regir igualmente en el ámbito local, como afirma la propia ORTEGA BERNARDO, J. (2016): "Derecho de defensa de la competencia y Administraciones Públicas: una visión crítica sobre las excepciones a la aplicación de las normas de la competencia a los Gobiernos Locales", en BAÑO LEÓN, J. M. (coord.): Memorial para la reforma del Estado: estudios en homenaje al Profesor Santiago Muñoz Machado, vol. III, pág. 2241. Madrid: Centro de Estudios Políticos y Constitucionales.

54 En esta misma línea se pronuncia GONZÁLEZ TORROBA, P. (2017): Cuando el Ayuntamiento hace la competencia. Servicio público local y Derecho de la Competencia. Navarra: Thomson Reuters Aranzadi, págs. 140-141. 
Por tanto, los servicios públicos de contenido económico, también los locales, se hallan igualmente sujetos al Derecho de la competencia, por expreso mandato del legislador europeo. La consideración de servicio público constituiría, en este sentido, un requisito necesario, pero no suficiente para dicha omisión. Es una realidad que la Administración como prestadora de servicios públicos de contenido económico compite con el resto de proveedores, por lo que el Derecho de la Competencia deberá seguir rigiendo en tanto no se entorpezca la misión específica. La excepción del artículo 106.2 TFUE, reflejada en el artículo 4 LDC, no se aplica como regla general a todos los servicios públicos de contenido económico sino, por el contrario, a título excepcional.

\section{B) Criterio teleológico}

Sentado lo anterior, resulta necesario entrar ahora en el análisis detallado de los fines perseguidos por los artículos 86 LRBRL y 97 TRRL para determinar si, efectivamente, el establecimiento de una actividad económica como servicio público debe someterse a los trámites procedimentales en ellos previstos. Nuestro punto de partida es la cláusula general contenida en ambos preceptos, según la cual el ente local deberá acreditar «la conveniencia y oportunidad de la medida». Esto es, el objetivo perseguido es claramente la motivación y justificación de la medida.

Respecto a la obligación de seguir el procedimiento atendiendo a este fin, podemos identificar entre la doctrina y la jurisprudencia tres posturas diferentes. Una parte de la doctrina, encabezada por Ortega Bernardo y respaldada por parte de la jurisprudencia ${ }^{55}$, mantiene que «no se requiere justificar la actividad administrativa para prestar un servicio público, dado que la propia ley, debido al interés público prevalente que se encuentra presente en ese ámbito, autoriza o impone (esto último en el caso de que se haya declarado servicio obligatorio) desarrollar dicha actividad ${ }^{56}$. Es decir, tanto la prestación de servicios facultativos 0 -potestativos- (artículo 25 LRBRL) como la de los servicios obligatorios (artículo 26 LRBRL), está justificada por decisión del legislador. Sin embargo, si la prestación de los servicios potestativos fuera, en todo caso, conveniente y oportuna, en todos los Municipios, ¿por qué el legislador no los ha establecido como obligatorios junto al resto del artículo 26 LRBRL?

Ante esta primera postura, aparece otra también respaldada por cierta jurisprudencia que, siguiendo la anterior reflexión, distingue ambos tipos de servicios incluyendo en el ámbito de aplicación del artículo 97 TRRL los servicios facultativos. En este sentido, el Tribunal Superior de Justicia de la Comunidad Valenciana afirma que el artículo 86.1 LRBRL está pensado para todos aquellos servicios no incluidos en el artículo 26.1 LRBRL, pero «no [es] exigible para los supuestos del ejercicio por el Municipio de un puro servicio público o competencia administrativa de ejercicio obligatorio ${ }^{57}$. Esta acreditación de la conveniencia y oportunidad estaría en línea con lo exigido por el artículo 35.1 i) LPACAP, que establece como requisito general la motivación de los actos administrativos; en concreto, de «los actos que se dicten en el ejercicio de potestades discrecionales». De esta manera, se reforzaría este deber de motivación que, en lugar de satisfacerse con una "sucinta referencia de hechos y fundamentos de derecho», debería cumplirse a través de la preceptiva redacción de una memoria y con su exposición pública.

Frente a estas dos tesis, encontramos una tercera defendida, entre otros, por Ezquerra Huerva, la cual entiende que los servicios públicos, independientemente de su naturaleza facultativa u obligatoria, deben someterse a los trámites del artículo 97 TRRL. Respecto a este objetivo general, desde nuestro punto de vista, el hecho de que el legislador declare una actividad como servicio público o, incluso, como servicio obligatorio, no implica que su prestación sea conveniente y oportuna independientemente de cómo se lleve a cabo, sino que se deberá prestar de acuerdo al resto de fines que se persiguen y que se explican a continuación.

55 Recuérdense las ya referidas SSTSJ de Andalucía 355/2017, de 3 de abril (rec. 464/2016), y 362/2017, de 30 de marzo (rec. 642/2016) en las que se mantuvo que «si estaba exclusivamente destinado a la práctica de la actividad deportiva del golf, también queda justificada la prestación de un servicio público de competencia municipal mediante una sociedad mercantil local sin tener que tramitar expediente de municipalización» (FJ 3).

56 ORTEGA BERNARDO, J. (2006): "Competencias, servicios públicos y actividad económica de los Municipios: (Presupuestos actuales para su delimitación y su ejercicio)", cit., pág. 80.

57 STSJ de la Comunidad Valenciana 1674/2000, de 15 de diciembre (rec. 837/1998), FJ 2. En este caso se discutía sobre la necesidad de seguir la tramitación del artículo 86 LRBRL para la constitución de un consorcio en la provincia de Alicante para la gestión de los residuos sólidos urbanos del Baix Vinalopó. En la misma línea se muestra el Juzgado Contencioso-administrativo núm. 3 de Valladolid en su sentencia 150/2017, de 14 de noviembre (rec. 14/2017), en donde se discutía sobre la asunción de la gestión del servicio de abastecimiento de aguas del Municipio de Valladolid por parte del Ayuntamiento mediante una Entidad pública empresarial. 
Es decir, la acreditación de la «oportunidad y conveniencia» dependerá, también y en buena medida, de cómo se afronten los otros objetivos perseguidos con el procedimiento de los artículos 86 LRBRL y 97 TRRL.

En efecto, de la lectura de tales artículos se extraen, al menos, otros tres fines, más concretos, que se enmarcarían dentro del general sobre la motivación de la medida, a saber: a) la estabilidad presupuestaria y la sostenibilidad financiera, b) la defensa de la competencia en y por el mercado, y c) la participación de la ciudadanía en las decisiones locales. Veamos a qué nos estamos refiriendo.

Por un lado, tras la crisis económica de 2008 se percibe en el legislador estatal una gran preocupación por el control del gasto público que, como ya se ha mencionado, se ha reflejado en la Ley Orgánica 2/2012, de 27 de abril, de Estabilidad Presupuestaria y Sostenibilidad Financiera y en la Ley 27/2013, de 27 de diciembre, de racionalización y sostenibilidad de la Administración Local, que modifica, entre otros, el artículo 86 LRBRL. Con esta modificación se impone un límite muy claro, casi absoluto, al desarrollo de actividades económicas por parte de las Administraciones locales: «no generar riesgo para la sostenibilidad financiero del conjunto de la Hacienda municipal». Así parece que, por muy conveniente que sea su prestación en abstracto, esta tendrá que ser respetuosa con la estabilidad y sostenibilidad financiera del ente local.

El segundo fin es la defensa de la competencia, objetivo fundamental en nuestro ordenamiento jurídico. Esto hace necesaria una ponderación entre el interés general derivado de la prestación de un servicio público por parte de la Administración, y el impacto en la competencia. Como ya se ha reflexionado con ocasión de la Sentencia del Tribunal Superior de Castilla y León 1241/2017, la Administración opera, con carácter general, como un competidor más en el mercado también cuando se trata de servicios públicos económicos ${ }^{58}$. El procedimiento previsto en el artículo 86 LRBRL, por lo tanto, también pretende garantizar el respeto a las normas de la competencia. Por todo ello, compartimos las palabras de Ezquerra Huerva, para quien «el carácter económico de la actividad que pretenda llevar a cabo la Administración local, y no su condición o carácter de servicio público o no, es por tanto el criterio que se muestra como decisivo en orden a entender que la prestación del servicio por parte del Municipio requiere de la tramitación prevista para el desempeño de actividades económicas» ${ }^{59}$.

Por último, un tercer objetivo, en absoluto desdeñable, es la promoción de la participación ciudadana en la toma de decisiones de la Corporación Local a través de la exposición pública de la memoria, como ya se indicó.

Una vez analizados estos fines debemos concluir que los servicios públicos, incluidos aquellos de carácter obligatorio, deben someterse al procedimiento establecido en los artículos 86 LRBRL y 97 TRRL, ya que este no persigue solo la simple acreditación de la conveniencia de su prestación, sino también la salvaguarda de otros objetivos que justificarán esta conveniencia. Así, de la declaración de servicio público no se puede deducir que no se afecte el mercado o que esta afección esté justificada ${ }^{60}$, ni que no se genere riesgo para la estabilidad del Ente local. La preocupación mostrada por el legislador por esta no hace posible obviar este riesgo por la declaración de servicio público, ni siquiera como obligatorio. Tampoco se justifica, por ser servicio público, la omisión de la exposición pública con la que se priva al ciudadano de participar en servicios tan importantes para la colectividad, menos aún, cuando se trata de servicios obligatorios. Poca lógica tendría que, teniendo los vecinos el derecho de exigir estos últimos [art. $18.1 \mathrm{~g}$ ) LRBRL], dispongan de menos posibilidades para participar en la implantación de aquellos.

\section{C) En particular, la prestación de servicios obligatorios}

Desde nuestro punto de vista, la controversia entre las tres tesis que acabamos de analizar radica en el, a priori, conflicto de normas derivado de la obligatoriedad de los servicios del artículo 26 LRBRL y el límite absoluto de no generar riesgo para sostenibilidad financiera de la Hacienda Local. ¿Podría anularse el acuerdo que aprobase la prestación de un servicio obligatorio que generase un riesgo para la sostenibilidad financiera? A nuestro entender, y a la vista de la normativa vigente, la respuesta debe ser afirmativa. Primero, debería comprobarse si hay otra configuración del servicio que no genere ese riesgo. Para el caso negativo, esto es, que el Municipio no tenga opción de prestar el servicio sin incurrir en este riesgo, tanto el legislador estatal como el autonómico han previsto alternativas.

58 Vid. COLOMÉ I NIN, A. y GRAU I ARNAU, S. (2017): “"Remunicipalización» de servicios locales y competencia”, en Cuadernos de Derecho Local, QDL, núm. 43, cit., págs. 131-132.

59 EZQUERRA HUERVA, A. (2017): "Sobre el procedimiento administrativo a seguir para la remunicipalización de servicios", cit., pág. 8.

60 Por ello, se requiere, precisamente, un análisis de mercado en el que se justifique la eventual afección al mercado, ponderando los intereses contrapuestos. 
Así, podemos observar el inciso de la anterior redacción del artículo 26.1 LRBRL que indica que los Municipios «por sí o asociados» deberán prestar los servicios que se señalan en el mismo. Con la reforma de la LRBRL esta cooperación entre las Administraciones se ha reforzado, estableciéndose en su apartado segundo que «para coordinar la citada prestación de servicios la Diputación propondrá, con la conformidad de los Municipios afectados, la forma de prestación, consistente en la prestación directa por la Diputación o la implantación de fórmulas de gestión compartida a través de consorcios, mancomunidades u otras fórmulas». En efecto, el artículo 44.1 LRBRL «reconoce a los Municipios el derecho a asociarse con otros en mancomunidades para la ejecución en común de obras y servicios determinados de su competencia». E, igualmente, el artículo 57 LRBRL regula los consorcios y los convenios para «la cooperación económica, técnica y administrativa entre la Administración local y las Administraciones del Estado y de las Comunidades Autónomas». Además, recordemos que, el legislador estatal estableció como razón de ser y competencia propia y específica de la Provincia «asegurar la prestacion integral y adecuada en la totalidad del territorio provincial de los servicios de competencia municipal» [artículo 31.2 a) LRBRL], así como la «asistencia y cooperación jurídica, económica y técnica a los Municipios, especialmente los de menor capacidad económica y de gestión» [artículo 36.1 a) y b) LRBRL]. En definitiva, el Municipio que no sea capaz de prestar un servicio por sí mismo podrá asociarse con otras Administraciones, locales, autonómicas o estatal para prestarlo y contar, en todo caso, con la Diputación, que se configura como el responsable de asegurar la prestación de los servicios locales ${ }^{61}$.

\section{D) La dudosa ratio decidendi del Tribunal Supremo: la naturaleza mercantil de la entidad prestadora}

Por último, es de obligada mención el criterio decisorio utilizado por el Tribunal Supremo, con posterioridad a la STS de 23 de mayo de $1997^{62}$, para la aplicación del procedimiento relativo al ejercicio de actividades económicas. En dos casos relativos a la creación de una sociedad mercantil local para la prestación de un servicio público esencial utiliza como ratio decidendi el carácter mercantil de la sociedad, sosteniendo que «la necesidad de previo expediente acreditativo de la conveniencia y oportunidad (...) es común a todos los casos de creación de empresas mercantiles para la gestión de servicios públicos», justificándolo en el "carácter excepcional que, desde el punto de vista de los principios de libre empresa y libertad de mercado (artículo $38 \mathrm{CE}$ ) reviste la intervención pública en la actividad económica (artículo $128 \mathrm{CE}$ )». Dicha creación de una empresa sujeta al Derecho mercantil supone una «sustracción a los principios del Derecho público, cualquiera que sea la significación de las actividades de interés público a que se dedique su actividad» ${ }^{63}$.

Aunque tenga lógica, en abstracto, y guarde cierta relación con el criterio del «carácter económico» de Ezquerra Huerva, este razonamiento nos plantea algunas dudas jurídicas, de tal modo que no podemos compartirlo ${ }^{64}$. Por un lado, el artículo 85 LRBRL, en su anterior redacción, no diferenciaba entre las formas

61 Como afirmó el Consejo de Estado en su Dictamen 567/2013 sobre el Anteproyecto de Ley de racionalización y sostenibilidad de la Administración local $\left(\S 1 .^{\circ}\right)$, uno de los principales objetivos de la LRSAL era fortalecer las Diputaciones provinciales, ampliando sus competencias, con el fin de lograr economías de escala con unos servicios comunes centralizados. A este respecto, vid. GRACIA RETORTILLO, R. (2016): "Racionalización y sostenibilidad de la administración local en España: una reforma frustrada. Las competencias provinciales como paradigma", en Istituzioni del Federalismo: Rivista di Studi Giuridici e Politici, núm. 4, págs. 951-953. Este reforzamiento de las competencias de las Diputaciones en perjuicio de las competencias municipales ha sido objeto de una amplia crítica. De hecho, fueron abundantes los recursos de inconstitucionalidad referidos a preceptos de la LRBRL que habían sido modificados por la LRSAL en los que se refuerzan y amplían las competencias de las Diputaciones a costa de las competencias municipales, en detrimento de la autonomía local consagrada en la Constitución, según argumentaron los recurrentes. Sin embargo, el Tribunal Constitucional ha manifestado que la ampliación competencial efectuada en favor de las Diputaciones es compatible con la autonomía municipal protegida por la Constitución. Véanse las SSTC 41/2016, de 3 de marzo; 111/2016, de 9 de junio; 101/2017, de 20 de julio; y 107/2017, de 21 de septiembre; entre otras. Las dos primeras sentencias se han estudiado extensamente por la doctrina administrativista entre la que cabe mencionar a MEDINA ALCOZ, L. (2016): "La distribución de competencias entre el Estado y las comunidades autónomas a la luz de las sentencias constitucionales sobre la reforma local de 2013", págs. 189-224, y GRACIA RETORTILLO, R. (2016): "La LRSAL ante el Tribunal Constitucional: la afectación a la autonomía local", págs. 225-280, ambos en Anuario del Gobierno Local, 2016; y VELASCO CABALLERO, F. (2016): “Juicio constitucional sobre la LRSAL: punto final”, en Anuario de Derecho Municipal, núm. 10, págs. 22-44.

62 Vid. nota 47.

63 SSTS de 1 de febrero de 2002 (rec. 6139/1996), FJ 2 y 5, y de 4 de julio de 2003 (rec. 8954/1997), FJ 1. Ambos casos consistieron en la creación de una sociedad mercantil para hacerse cargo del servicio de recogida de basuras y limpieza viaria del Municipio, siendo de capital público la primera y de capital mixto la segunda. Esto lo entiende suficiente el Tribunal para aplicar los artículos 86 LRBRL y 97 TRRL.

64 De la misma opinión, ORTEGA BERNARDO, J. (2006): "Competencias, servicios públicos y actividad económica de los Municipios: (Presupuestos actuales para su delimitación y su ejercicio)" cit., págs. 80-81. 
de gestión a disposición del Ente local, siendo la sociedad mercantil pública una de ellas (letra d). Por otro lado, de la lectura de los artículos citados no se puede extraer como fin declarado del procedimiento una fiscalización mayor para el caso de la creación de sociedades mercantiles. Por tanto, aunque coincidimos en el fallo no compartimos el razonamiento jurídico llevado a cabo por el Tribunal. En nuestra opinión, lo que justifica el sometimiento al procedimiento del artículo 86 LRBRL y 97 TRRL es que la Corporación Local quiera emprender una actividad económica, y no el carácter mercantil de la sociedad a través de la cual se realizará dicha actividad.

\subsection{La aplicación del procedimiento de los artículos 86 LRBRL y 97 TRRL a los cambios de gestión en la prestación de servicios públicos}

Cuestion distinta a los casos de municipalización en sentido amplio son los supuestos de externalización y (re)internalización -o (re)municipalización-. Nos referimos al caso en el que, una vez realizada la asunción o establecimiento de un servicio de acuerdo con el artículo 97 TRRL, se cambia la gestión establecida en un primer momento. Hablaríamos, así, de externalización en los casos en los que se cambia de gestión directa a indirecta, y de internalización o municipalización, en sentido estricto, en el caso contrario. Cuando esta última tiene lugar una vez ya había sido prestado el servicio en un primer momento mediante gestión directa, estamos ante un caso de remunicipalización o reinternalización.

La cuestión que debe resolverse en este supuesto es si este cambio en el modo de gestión «entraña el ejercicio de una actividad económica por parte de la Entidad Local que ha de incardinarse en el artículo 97.1 TRRL, o si, por el contrario, dicho cambio de gestión indirecta a directa, o viceversa, puede considerarse como un servicio público de competencia de la Entidad Local sujeto a la libre potestad organizadora que a esta última le confiere el artículo $30 \mathrm{RSCL}$ e incluible en la noción que incorpora el artículo 85 LRBRL» ${ }^{65}$.

Desde un punto de vista estrictamente gramatical, el artículo 97.1 TRRL se refiere al «ejercicio de actividades económicas», mientras el artículo 86.1 LRBRL concreta algo más, aludiendo al ejercicio de «la iniciativa pública para el desarrollo de actividades económicas». En principio, podría pensarse que estos artículos se refieren a la declaración de servicio público, esto es, la asunción de la prestación del servicio. En esta línea, sus respectivos apartados segundos hablan de «la efectiva ejecución de estas actividades» en caso de monopolio ${ }^{66}$, lo que ha llevado a parte de la jurisprudencia a concluir que el artículo 86 LRBRL no resulta aplicable por entender que «la decisión sobre la forma de gestión no es una decisión sobre el ejercicio de la iniciativa pública respecto a una actividad económica» ${ }^{67}$.

En segundo lugar, sin embargo, desde un punto de vista sistemático y teleológico se debe reparar en que la regulación del establecimiento del servicio que hacen los artículos 86 LRBRL y 97 TRRL exige una planificación completa de la vida del mismo. De esta manera, ambos artículos requieren tanto la determinación de la forma concreta de gestión como también la determinación de «los casos en que debe cesar la prestación de la actividad» [artículo 97.1 b) LRBRL]. En atención a estas exigencias, habría que preguntarse si con el nuevo modo de gestión es conveniente y oportuno ejercer la actividad económica; si esta genera ahora riesgo para la sostenibilidad financiera del conjunto de la Hacienda municipal; qué repercusiones puede tener para la competencia; y si no sería conveniente que los vecinos tuviesen de nuevo la oportunidad de dar su opinión sobre el servicio y su configuración.

De esta opinión es Ezquerra Huerva, quien defiende que «la forma de gestión no se presenta en la legislación vigente como un dato adjetivo o secundario", sino que "aparece como uno de los elementos centrales

65 Así se manifiesta la STSJ de Canarias 114/2009, de 15 de septiembre (rec. 96/2009), FJ 1. Tras la LRSAL, en 2013, esta «libre» potestad organizadora ha sido alterada, como se dirá en el epígrafe III.

66 Según esto, el Tribunal Superior de Justicia de Castilla y León afirmó que «el modo de gestión no afecta a la prestación del servicio en régimen de monopolio» y, por tanto, «no es aplicable al caso enjuiciado el último inciso del artículo 86.3 de la Ley de Bases». Vid. STSJ de Castilla y León 2260/2012, de 28 de diciembre (rec. 1435/2010), FJ 5. Se impugnaba la creación de una Sociedad de economía mixta para la gestión del Servicio Municipal de Abastecimiento de Aguas de León que estaba gestionando hasta el momento el Ayuntamiento. El Tribunal concluye que «el proceso seguido no es el de municipalización, pues el servicio de abastecimiento de aguas ya se prestaba con carácter de monopolio por el Ayuntamiento». Esta sentencia fue objeto de casación, en el que la STS de 23 de febrero de 2015 (rec. 595/2013) se mostró de acuerdo con esta interpretación.

67 Así lo recoje y sostiene el Juzgado de lo Contencioso-administrativo núm. 3 de Valladolid en la SJCA núm. 3 de Valladolid 150/2017, de 14 de noviembre (rec. 14/2017), FJ 5. En esta misma línea, COLOMÉ I NIN, A. y GRAU I ARNAU, S. (2017): “«Remunicipalización» de servicios locales y competencia”, cit., págs. 155-156. 
o nucleares de la decisión administrativa local de llevar a cabo una actividad de contenido económico» ${ }^{68}$. Además, dicho autor refuerza su posición resaltando la similitud más que evidente entre la estructura del artículo 97 TRRL y la del procedimiento de municipalización -entendida como la asunción de la gestión directa- establecido en el $\mathrm{RSCL}^{69}$. Similitud de la que deduce que el procedimiento del Reglamento constituye el desarrollo reglamentario del artículo $97 \mathrm{TRRL}^{70}$. Siguiendo con este razonamiento, si el objeto de la municipalización definida en el artículo 45 RSCL es la asuncion de la gestión directa, el cambio de gestión debe incardinarse igualmente en el objeto del artículo 97 TRRL y, por ende, del artículo 86 LRBRL.

Por otra parte, ya se ha analizado la posición del TS en las Sentencias de 1 de febrero de 2002 y de 4 de julio de 2003 (vid. nota 63), donde defendía la aplicación de dichos artículos al cambio de gestión de un servicio público cuando se crease una sociedad mercantil precisamente por su forma jurídica privada y no pública. Más recientemente se ha pronunciado también en relación con la creación de una Sociedad de economía mixta, mediante la venta de la casi totalidad de la Sociedad pública que venía prestando el servicio municipal de aguas. En este caso, entendió que la venta de las acciones de la empresa pública constituía una actividad económica y que, por tanto, era de aplicación el artículo 97 TRRL ${ }^{71}$. Como señalamos en su momento, en nuestra opinión los artículos 86 LRBRL y 97 TRRL no prevén como causa de aplicación del procedimiento la naturaleza mercantil de la entidad mediante la que se gestiona el servicio.

En definitiva, resulta evidente que la literalidad del texto normativo no es todo lo clara que sería deseable. No obstante, el papel central que ocupa la elección del modo de gestión en el procedimiento de los artículos 86 LRBRL y 97 TRRL hace pensar que el cambio de gestión de un servicio público debe incardinarse dentro del ámbito de aplicación de dicho procedimiento.

\section{SOBRE LA GESTIÓN DEL SERVICIO: EL ARTÍCULO 85 LRBRL}

En páginas anteriores ya se pudo apreciar la importancia que tiene la decisión sobre la forma o el modo en que se decide prestar el servicio. De hecho, esta cuestión será decisiva para que los Tribunales resuelvan sobre la conveniencia y oportunidad de la iniciativa pública ejercida por una Administración local al amparo de los artículos 86 LRBRL y 97 TRRL. El objeto del presente epígrafe es, precisamente, el estudio del artículo 85 LRBRL, que regula las diferentes formas o modos de gestión de las que dispone la Entidad local para prestar los servicios públicos de su competencia. Nos centraremos en el impacto que sobre este precepto ha tenido la reforma operada por la LRSAL, en línea con la LOEPSF. En primer lugar, se expondrá brevemente la situación previa a dicha reforma. En segundo lugar, se analizarán los requisitos introducidos por la LRSAL. Y, por último, se reflexionará sobre las consecuencias derivadas de la introducción de nuevos requisitos como resultado de aquella modificación.

\section{La reforma del artículo 85 LRBRL y la reducción de la discrecionalidad de la forma de gestión}

Como es conocido, el artículo 85 LRBRL se dividía en su anterior redacción en tres apartados. En el primero se delimitaba su ámbito de aplicación, en el segundo se enumeraban las diferentes formas de gestión posibles de un servicio público, limitándose estas en el tercer apartado en el caso de los servicios que implicaran ejercicio de autoridad.

En cuanto a los distintos modos de gestión, el legislador otorgaba un gran margen de discrecionalidad a la Administración local que prestaba el servicio para decidir el más adecuado para realizar la actividad de

68 EZQUERRA HUERVA, A. (2017): "Sobre el procedimiento administrativo a seguir para la remunicipalización de servicios", cit., pág. 9-11.

69 Artículos 56 a 63 que desarrollan el contenido que, según el artículo 97 TRRL, debe contener la memoria acreditativa de la conveniencia y oportunidad, así como su sometimiento a información pública.

70 Se debe matizar que los artículos $45 \mathrm{RSCL}$, donde se define la municipalización, y 97 TRRL responden a diferentes criterios de aplicación. Mientras que el objeto del artículo 45 RSCL es la asunción del riesgo empresarial por parte de la Administración local, el del artículo 97 TRRL es las «actividades económicas». Así, la prestación de un servicio público mediante un contrato de concesión de servicios públicos -en el cual es el concesionario quien asume el riesgo operacional (artículo 15.2 LCSP) - estaría sometida a lo establecido en el artículo 97 TRRL, pero no al procedimiento de municipalización del RSCL. Por tanto, el RSCL constituye, en su caso, el desarrollo reglamentario parcial del artículo 97 TRRL.

71 STS de 20 de noviembre de 2012 (rec. 80/2009), confirmando lo dicho por la STSJ de Canarias 114/2009, de 15 de septiembre (rec. 96/2009) (vid. nota 34). 
que se tratase, enmarcando esta decision dentro de la potestad autoorganizativa de los Entes locales [artículos 4.1 a) LRBRL y $30 \mathrm{RSCL}^{72}$. Ese margen de discrecionalidad se reducía, no obstante, cuando se trataba de servicios públicos que implicaban ejercicio de autoridad, que solo podían ser gestionados por la propia Entidad local, un Organismo autónomo o una Entidad pública empresarial. Debido a la naturaleza de estos servicios, el legislador entendía que quienes los gestionasen debían ser funcionarios públicos y su régimen sujetarse al Derecho Administrativo.

Con la nueva redacción dada por la LRSAL, ni el ámbito de aplicación ni la limitación relativa a los servicios públicos que implican ejercicio de autoridad se han visto alterados de forma sustancial, si bien esta última limitación se expresa ahora en otros términos. Donde ha tenido verdadera repercusión dicha reforma, bastante discutida, ha sido en su apartado segundo, que ha quedado redactado de la siguiente forma:

Los servicios públicos de competencia local habrán de gestionarse de la forma más sostenible y eficiente de entre las enumeradas a continuación:

A) Gestión directa:

a) Gestión por la propia Entidad Local.

b) Organismo autónomo local.

c) Entidad pública empresarial local.

d) Sociedad mercantil local, cuyo capital social sea de titularidad pública.

Solo podrá hacerse uso de las formas previstas en las letras $c$ ) y d) cuando quede acreditado mediante memoria justificativa elaborada al efecto que resultan más sostenibles y eficientes que las formas dispuestas en las letras a) y b), para lo que se deberán tener en cuenta los criterios de rentabilidad económica y recuperación de la inversión. Además, deberá constar en el expediente la memoria justificativa del asesoramiento recibido que se elevará al Pleno para su aprobación en donde se incluirán los informes sobre el coste del servicio, así como, el apoyo técnico recibido, que deberán ser publicitados. A estos efectos, se recabará informe del interventor local quien valorará la sostenibilidad financiera de las propuestas planteadas, de conformidad con lo previsto en el artículo 4 de la Ley Orgánica 2/2012, de 27 de abril, de Estabilidad Presupuestaria y Sostenibilidad Financiera.

B) Gestión indirecta, mediante las distintas formas previstas para el contrato de gestión de servicios públicos en el texto refundido de la Ley de Contratos del Sector Público, aprobado por Real Decreto Legislativo 3/2011, de 14 de noviembre.

$$
\text { (...). }
$$

Así, observamos que se ha introducido un criterio general de carácter material y una serie de criterios particulares -formales- para determinados modos, que estudiaremos a continuación.

\subsection{Requisitos materiales del artículo 85 LRBRL: La sostenibilidad y eficiencia}

Como se puede apreciar en el artículo 85 , el criterio general de carácter material se concreta en la elección del modo de gestión más sostenible y eficiente. Así pues, igual que acudimos anteriormente a la LOEPSF para saber qué debíamos entender por estabilidad presupuestaria y sostenibilidad financiera, parece razonable hacer ahora lo mismo con el término eficiencia, regulado en el artículo $7^{73}$. Sin embargo,

72 En esta línea, la STSJ de Castilla y León 2260/2012, de 28 de diciembre (rec. 1435/2010), FJ 4. Igualmente, SOSA WAGNER, F. (2007): "Artículo 85", en REBOLLO PUIG, M. (dir.) e IZQUIERDO CARRASCO, M. (coord.): Comentarios a la Ley Reguladora de las Bases del Régimen Local, vol. II, págs. 2.257-2.300. Valencia: Tirant lo Blanch, pág. 2261. El autor afirmaba que «las formas de gestión de servicios son una expresión de la autonomía local y, en concreto de la potestad de autoorganización, la más significada seña de identidad de esa autonomía».

73 Así lo hacen, entre otros, VILLAR ROJAS, F. J. (2016): "Implicaciones de los principios de sostenibilidad y estabilidad presupuestaria en los modos de gestión de los servicios públicos locales”, en El Cronista del Estado Social y Democrático de Derecho, núm. 58-59, pág. 103; TORNOS MAS, J. (2017): "La llamada remunicipalización de los servicios públicos locales. Algunas precisiones conceptuales", cit., pág. 58; y ESTEVE PARDO, J. (2017): "Perspectivas y cauces procedimentales de la remunicipalización de servicios", cit., pág. 333. En el mismo sentido también la jurisprudencia, por ejemplo en la sentencia del Juzgado de lo Contencioso-administrativo núm. 3 de Valladolid, sentencia 150/2017, de 14 de noviembre (rec. 14/2017), FJ 4. A este respecto, el Tribunal hace notar la relación de la eficiencia con los criterios del artículo 133 LRBRL, entre los que aparece el de «estabilidad presupuestaria» (letra a). 
como destaca Villar Rojas ${ }^{74}$, el artículo no da una definición del término sino que enumera un conjunto de principios generales que deben de observarse en la gestión de los recursos públicos, tales como la eficacia, la propia eficiencia o la economía (recogidos en el artículo 31.2 CE) y, cómo no, los principios de estabilidad presupuestaria y sostenibilidad financiera. Ante esta falta de concreción, debemos entender por eficiencia la consecución del objetivo prefijado con el menor número de recursos posible.

Por su parte, ya hicimos referencia al concepto de sostenibilidad de acuerdo al artículo 4.2 LOEPSF, que la define como «la capacidad para financiar compromisos de gasto presentes y futuros dentro de los límites de déficit, deuda pública y morosidad de deuda comercial conforme a lo establecido en esta Ley, la normativa sobre morosidad y en la normativa europea». Por tanto, en palabras de Tornos Mas, el artículo 85.2 LRBRL «vincula al ente local a tener que buscar la fórmula no solo más eficiente sino también más sostenible, es decir, aquella que responda a los criterios económicos de no incremento de la deuda y posibilidad de gestión con un presupuesto equilibrado» ${ }^{75}$. Respecto a la interpretación sobre la sostenibilidad exigida del modo de gestión, Villar Rojas ${ }^{76}$ parece entender que el artículo 85.2 LRBRL exige que el servicio público resultante debe ser sostenible por sí mismo, criticando esta exigencia por cuanto la LOEPSF siempre se refiere a la sostenibilidad del conjunto de la Hacienda local.

Si reparamos en la literalidad del artículo 85 , este exige que el servicio sea el más sostenible. Esto nos lleva a dos conclusiones. La primera es que la Corporación local no tiene varias opciones igualmente válidas, sino que solo una será conforme a Derecho, aquella gestión que sea la más sostenible. Esta conclusión será abordada en el siguiente epígrafe.

La segunda, en relación a lo dicho por Villar Rojas, es que la sostenibilidad no se configura como un criterio absoluto sino relativo ${ }^{77}$. Esto es, la norma establece que la forma de gestión tiene que ser la más sostenible (de entre las opciones de las que disponga la Administración local), incluyendo la forma de gestión menos insostenible (por sí misma) si todas ellas resultasen ser insostenibles. En definitiva, la norma no exige que la gestión sea sostenible, sino la más sostenible o, en otros casos, la menos insostenible.

Esta conclusión encajaría con el resto del ordenamiento y la lógica de la prestación de servicios públicos. Recuérdese, en este sentido, que el artículo 44 LRHL admite la prestación de servicios por debajo del coste cuando existan «razones sociales, benéficas, culturales o de interés público». A mayor abundamiento, la referencia a la sostenibilidad se debe interpretar respecto al conjunto de la Hacienda Local no solo por la interpretación de la LOEPSF, sino por el mismo artículo 86.1 LRBRL, pues este obliga a que en el expediente acreditativo de la conveniencia y oportunidad de la medida se justifique «que la iniciativa no genera riesgo para la sostenibilidad financiera del conjunto de la Hacienda municipal». En definitiva, nuestro ordenamiento permite que el servicio público no sea sostenible por sí mismo. Eso sí, siempre que «no genere riesgo para la sostenibilidad financiera del conjunto de la Hacienda municipal».

Por último, es de destacar que el legislador precisa que, a la hora de valorar la mayor eficiencia y sostenibilidad de la gestión mediante Entidad pública empresarial o mediante Sociedad mercantil, «se deberán tener en cuenta los criterios de rentabilidad económica y recuperación de la inversión». Es evidente, en este sentido, que ambos deben considerarse simplemente principios orientadores, pues no en todos los casos serán coincidentes con los principios de eficiencia y sostenibilidad ${ }^{78}$. Además, también llama la atención que aquella precisión se haga únicamente respecto a estas dos fórmulas de gestión y no respecto al resto. Sin duda, las Entidades locales deberán tener en cuenta estos principios para todas las opciones. Aquí, el legislador presupone que estas dos opciones suponen una mayor inversión inicial y mayores gastos en la prestación. A nuestro entender, hubiera sido más oportuno haberlo establecido con carácter general.

74 VILLAR ROJAS, F. J. (2016): "Implicaciones de los principios de sostenibilidad y estabilidad presupuestaria en los modos de gestión de los servicios públicos locales", cit., pág. 103.

75 TORNOS MAS, J. (2017): "La remunicipalización de los servicios públicos locales”, cit., pág. 58. En este mismo sentido, GARCÍA RUBIO, F. (2017): "Pros y contras jurídico-administrativos de la «reinternalización» (remunicipalización) de servicios públicos”, cit. pág. 180

76 VILLAR ROJAS, F. J. (2016): "Implicaciones de los principios de sostenibilidad y estabilidad presupuestaria en los modos de gestión de los servicios públicos locales", cit., pág. 103.

77 En una línea similar, si bien respecto de la eficiencia, ORTEGA BERNARDO, J. y DE SANDE PÉREZ-BEDMAR, M. (2015): "EI debate sobre la remunicipalización de los servicios públicos: aspectos jurídicos, administrativos y laborales", cit., pág. 69, afirmando que esta «es un concepto esencialmente ponderativo: no responde a esquema de todo o nada, sino de más o menos».

${ }^{78}$ La gestión de un servicio puede resultar, por ejemplo, la más rentable pues se obtiene el mayor beneficio posible en proporción a lo invertido, pero, en cambio, no ser la más eficiente porque haya otra opción que, con menos recursos, consiga los mismos niveles de calidad, igualdad, etc. 


\subsection{Requisitos formales del artículo 85 LRBRL}

Además del principio material de la mayor sostenibilidad y eficiencia, las opciones de gestión directa de la Entidad pública empresarial y la Sociedad mercantil exigen el cumplimiento de tres requisitos formales: la elaboración de dos memorias, la elevación de estas al pleno para su aprobación y su publicación final.

En primer lugar, si el Ente local concluye que la opción más sostenible y eficiente es una de las dos citadas, deberá elaborar dos memorias. En la primera deberá acreditar la mayor sostenibilidad y eficiencia respecto a las opciones de la gestión por la propia Entidad local y mediante Organismo autónomo. Por su parte, en la segunda deberá justificar el asesoramiento recibido, recogiendo diversos informes sobre el coste del servicio, el apoyo técnico prestado y el del interventor local sobre la sostenibilidad financiera de todas las opciones. Todos estos informes son preceptivos, en especial, el del interventor local, aunque, y esto es importante, no son vinculantes, por aplicación de las reglas generales contenidas en el artículo 80.1 LPACAP. Además, como recuerda Ortega Bernardo ${ }^{79}$, el informe de este último será de legalidad y no de oportunidad, de acuerdo a lo dicho por el Tribunal Constitucional ${ }^{80}$.

En segundo lugar, ambas memorias, junto a los informes mencionados, deben ser aprobados por el Pleno por mayoría simple, por aplicación del artículo 47 LRBRL.

En tercer y último lugar, se ha de destacar el inciso «deberán ser publicitados». Este ha sido interpretado de formas diversas. Esteve Pardo coincide con Martínez-Alonso Camps en que la norma «exige un trámite de información pública, que se encontraba ya en algunas leyes autonómicas y era una reivindicación generalizada en la doctrina» ${ }^{81}$. Por el contrario, alguna sentencia reciente ha sostenido que "atendiendo a lo que se dispone en el artículo 85.2, esta publicación no es un trámite que debe cumplirse con carácter previo a la aprobación, sino que ha de producirse después de esa aprobación» ${ }^{82}$.

Por nuestra parte, a falta de una mayor claridad por parte del legislador, nos inclinamos por la posición de Esteve Pardo, pues resulta más acorde con la vocación de participación ciudadana en las Corporaciones locales y, en particular, en el Municipio.

\section{Consecuencias de la reforma del artículo 85 LRBRL}

\subsection{De una potestad discrecional a una potestad reglada}

Como adelantamos en el epígrafe anterior, desde la reforma operada por la LRSAL ya no habrá un abanico de opciones igualmente válidas entre las que pueda optar libremente la Entidad, sino que esta deberá examinar cada una de ellas y elegir la más sostenible y eficiente. Esto implica que el legislador ha introducido no un elemento reglado dentro de esta potestad (discrecional), que se enmarcaba a su vez dentro de la potestad autoorganizativa de la Entidad local, sino dos conceptos jurídicos indeterminados que deberán ser concretados en cada caso, apoyándose en otras ciencias no jurídicas, fundamentalmente en la Economía. De esta manera, el legislador ha cambiado la naturaleza de esta potestad ${ }^{83}$.

79 ORTEGA BERNARDO, J. y DE SANDE PÉREZ-BEDMAR, M. (2015): "El debate sobre la remunicipalización de los servicios públicos: aspectos jurídicos, administrativos y laborales", cit., pág. 69.

80 STC 143/2013, de 11 de julio (rec. 1598/2004), FJ. 10, en la que se resuelve el recurso interpuesto por el Consejo de Gobierno de la Generalitat de Cataluña contra la disposición final primera y el artículo primero de la Ley 57/2003, de 16 de diciembre, de medidas para la modernización del gobierno local, en cuanto da nueva redacción a varios artículos de la LRBRL. pág. 334

81 La cita en ESTEVE PARDO, J. (2017): "Perspectivas y cauces procedimentales de la remunicipalización de servicios", cit.,

82 STSJ de Castilla y León 150/2017, de 14 de noviembre (rec. 14/2017), FJ 4.

${ }^{83}$ ESTEVE PARDO, J. (2017): "Perspectivas y cauces procedimentales de la remunicipalización de servicios", cit., pág. 331, para quien «no se trata de una reducción del margen de discrecionalidad, sino de un cambio de órbita de la decision sobre el modo de gestión, pues de la órbita de la discrecionalidad pasa a la de los conceptos jurídicos indeterminados». En una línea similar, vid. GARRIDO JUNCAL, A. (2016): "Competencias y servicios públicos locales: el nuevo panorama en España tras la LRSAL", en Dereito: Revista Xurídica da Universidade de Santiago de Compostela, vol. 25, núm. extraordinario, XXX Aniversario de la Carta Europea de Autonomía Local, pág. 225. Debe insistirse en esta idea pues no puede confundirse el uso de los conceptos jurídicos indeterminados en el marco de una potestad reglada con el uso de una potestad discrecional. Mientras que en esta última la decisión de la Administración depende parcialmente de su voluntad, «la aplicación de conceptos jurídicos indeterminados es un caso de aplicación de la Ley», que consiste en un proceso intelectivo por parte de la Administración quien debe constatar la existencia de aquellos conceptos en el supuesto de hecho de que se trate (en nuestro caso, que el modo de gestión escogido sea efectivamente el más sostenible y eficiente). "En ese proceso intelectivo no interfiere la voluntad de la Administración". Vid. GARCÍA DE ENTERRÍA, E. y FERNÁNDEZ, T. R. (2015): Curso de Derecho Administrativo, vol. I. Navarra: Civitas Thomson Reuters, págs. 495 y ss. 
Este cambio de naturaleza lleva consigo otra consecuencia no menos importante: el control judicial. En efecto, recuerdan Ortega Bernardo y de Sande Pérez-Bedmar ${ }^{84}$, los criterios económicos que comentamos aquí apenas habían sido utilizados como norma de control judicial. Era difícil ver que la inobservancia de estos criterios se tradujera en una declaración de invalidez de la decisión administrativa. Ahora, en cambio, al haber una única opción conforme a dichos criterios económicos, se admite la plena revisión judicial de la resolución administrativa, como concluye igualmente Esteve Pardo ${ }^{85}$.

En este sentido, se ha comenzado a observar, en los últimos tiempos, un control exhaustivo por parte de los Tribunales ${ }^{86}$, quienes ahora no solo deben comprobar que la decisión se haya motivado y no sea arbitraria o irracional, sino que la misma debe llevar al juez a concluir que aquella es, en efecto, la forma más sostenible y eficiente.

No obstante, este control judicial no será fácil, no solo por la complejidad de los criterios económicos tenidos en cuenta en la toma de decisión ${ }^{87}$ sino, también, por la supeditación, por definición, de la eficiencia frente a la eficacia en tanto que la primera no existirá sin la segunda, y dado que la segunda depende de los objetivos establecidos. De esta forma, el establecimiento de unos objetivos u otros será decisivo en la forma de gestión seleccionada. Por ello, en tanto que la fijación de los objetivos de la prestación del servicio sea una potestad discrecional [artículos 4.1 a) LRBRL y $30 \mathrm{RSCL}$ ] que puedan incardinarse dentro de «las aspiraciones de la comunidad vecinal» (artículo 25.1 LRBRL), la potestad reglada de la búsqueda de la gestión más eficiente podría diluirse. Para evitar esto, los tribunales deberían ser exigentes respecto a la claridad del procedimiento. El primer paso de este no puede ser otro que el estudio de la situación del servicio y el establecimiento de los objetivos de este. Una vez establecidos aquellos, se deberá proceder al estudio de cada una de las formas de gestión sin distinción alguna. Y, finalmente, se escogerá aquella que en dichos estudios haya demostrado ser la más eficiente y sostenible.

\section{2. ¿La preferencia por la gestión indirecta frente a la directa?}

El establecimiento de los requisitos relativos a la sostenibilidad y a la eficiencia -más vinculados tradicionalmente al sector privado que al público- en lugar de otros como la calidad o asequibilidad, así como las exigencias formales establecidos únicamente para las opciones de gestión directa empresariales (Entidad pública empresarial y Sociedad mercantil), ha llevado a concluir a parte de la doctrina ${ }^{88}$ que de la norma se deduce una preferencia por las formas de gestión indirecta. En esta línea fue muy clara la antigua Comisión Nacional de la Competencia en su informe sobre el Anteproyecto de la LRSAL, que afirmó que la gestión indirecta «resulta preferible para la competencia y la eficiencia frente a la constitución de entidades instrumentales de capital público o mixto» ${ }^{89}$.

${ }^{84}$ ORTEGA BERNARDO, J. y DE SANDE PÉREZ-BEDMAR, M. (2015): "El debate sobre la remunicipalización de los servicios públicos: aspectos jurídicos, administrativos y laborales", cit., pág. 69.

85 ESTEVE PARDO, J. (2017): "Perspectivas y cauces procedimentales de la remunicipalización de servicios", cit., pág. 332 . De esta manera, el artículo 85 LRBRL se convierte en una auténtica «norma de control» y no solo en una «norma de conducta», utilizando los términos en los que se expresa José María Rodríguez de Santiago. Es decir, los criterios de eficiencia y sostenibilidad no serán únicamente orientadores de la conducta de la Administración, sino que permitirán su control por parte de los Tribunales. Sobre este tipo de normas y su relación con la discrecionalidad de la Administración puede verse su obra RODRÍGUEZ DE SANTIAGO, J. M. (2016): Metodología del Derecho administrativo: reglas de racionalidad para la adopción y el control de la decisión administrativa. Madrid: Marcial Pons, en especial, pág. 165 y ss.

${ }^{86}$ Así, podemos ver las SSTSJ de Cataluña 126/2016, de 9 de marzo (rec. 27/2013), 127/2016 (rec. 364/2012), $128 / 2016$ (rec. 371/2012) y 129/2016 (rec. 404/2012), estas tres últimas de 10 de marzo, todas ellas en relación a la impugnación del acuerdo por la que se aprueba la creación de una Sociedad de economía mixta para prestar el ciclo integral del agua del Area Metropolitana de Barcelona, sociedad resultante del convenio entre el Área Metropolitana de Barcelona y la Sociedad General d'Aigües de Barcelona, S. A. También, la STSJ de Baleares 391/2015, de 10 de junio (rec. 268/2014) relativa a la impugnación de una Ordenanza Municipal en la que el Ayuntamiento de Calvià (Mallorca) asume el servicio de recogida de residuos municipales.

${ }^{87}$ A este respecto, Blanquer Criado mantiene que no hay «criterios objetivos para discernir "ex ante", y con absoluta certeza, cuál es la fórmula ideal o el modo de gestión óptimo», pues «hay que reconocer que los métodos de evaluación del grado de acierto de ese tipo de decisiones, son escasamente fiables, y discutibles en sus resultados. Así lo demuestra la experiencia inglesa en su búsqueda del best value for money mediante el uso de herramientas de evaluación comparativa de las distintas fórmulas para gestionar un servicio (como el llamado Public Sector Comparator)». Cfr. BLANQUER CRIADO, D. V. (2012): La concesión de servicio público. Valencia: Tirant lo Blanch, págs. 387 y 388.

88 Vid. ESTEVE PARDO, J. (2017): "Perspectivas y cauces procedimentales de la remunicipalización de servicios", cit., págs. 331 333, y VILLAR ROJAS, F. J. (2016): "Implicaciones de los principios de sostenibilidad y estabilidad presupuestaria en los modos de gestión de los servicios públicos locales", cit., págs. 104-105.

89 Informe de 13 de marzo de 2013, sobre el Anteproyecto de Ley de Racionalización y Sostenibilidad de la Administración local, pág. 7. 
En contraposición a esta postura, es reseñable la del Juzgado núm. 3 de lo Contencioso administrativo de Valladolid que mantiene que «la gestión indirecta ha de considerarse subsidiaria respecto a la gestión directa» por cuanto «la Ley de Contratos del Sector Público exige respecto a la gestión indirecta una justificación expresa y un descarte de la opción directa» ${ }^{90}$. El Tribunal sigue el mismo razonamiento que la doctrina que defiende la preferencia de la norma por la gestión indirecta, pero sobre la base de otro artículado y, por tanto, con otro resultado. El Tribunal deduce que, al exigirse una estricta necesariedad de la contratación pública, para realizar un contrato de esta naturaleza (artículo 28 LCSP) ${ }^{91}$, y la motivación de la necesidad del contrato (artículo 116 LCSP), la LCSP antepone la gestión directa a la indirecta. En nuestra opinión, sin embargo, nada más lejos de la realidad, pues resultará necesaria la contratación pública en tanto una de sus modalidades resulte la forma de gestión más eficiente y sostenible.

Por nuestra parte, compartimos la posición de Colomé i Nin y Grau i Arnau, quienes defienden que, «aunque a priori, en términos de competencia, sería preferible optar por una gestión indirecta, ya que lleva asociado un mayor grado de competencia (los operadores rivalizan periódicamente para obtener el encargo de la Administración), no necesariamente siempre es la mejor opción; en ocasiones los beneficios derivados de una gestión [entendemos pública] eficiente pueden ser superiores a los derivados del juego de la competencia, por lo que si la gestión directa se demuestra más eficiente habrá que optar por ella» ${ }^{92}$. Por lo tanto, cuando una de las formas de gestión directa se demuestre más sostenible y eficiente que el resto de opciones, incluidas las de gestión indirecta, la Entidad local deberá optar por esta, y viceversa. No hay, desde un punto de vista estrictamente material, preferencia por una u otra forma de gestión ${ }^{93}$.

Por su parte, desde una perspectiva formal o procedimental, aunque, en un principio se observe una diferencia de trato destacada, en la práctica los requisitos relacionados con la motivación de las formas de gestión directa empresariales no resultan tan gravosos en relación al resto de opciones como en un principio puede parecer.

Resulta necesario tener presente el proceso de toma de decisión de la gestión con la que se va a prestar un determinado servicio público. Como se ha explicitado más arriba, la elección del modo de gestión ha dejado de ser una postestad discrecional de la Entidad local para convertirse en una potestad reglada en la que el legislador exige a la Coporación escoger aquella forma de gestión más sostenible y eficiente. Así pues, cuándo vaya a decidir sobre este extremo de la prestación se deberán analizar por igual todas y cada una de las opciones que recoge el artículo $85 \mathrm{LRBRL}$. A la hora de estudiar todos estos modos de gestión, normalmente la Coporacion solicitará asesoramiento externo y apoyo técnico respecto al servicio público que se trate, para valorar cada una de las posibilidades. Deberá hacer un estudio sobre el coste del servicio -imprescindible para valorar la conveniencia y oportunidad de la medida en conformidad con los artículos 86 LRBRL y 97 TRRL- según la forma de gestión por la que opte. Por tanto, ni la acreditación de ser la forma de gestión sostenible y eficiente -requisito este que se exige con carácter general-, ni los informes del asesoramiento y el apoyo técnico recibido y aquel sobre el coste del servicio suponen un plus en cuanto a la motivación de la elección de la gestión mediante Entidad pública empresarial o Sociedad mercantil local. Todos estos informes deben estar presentes en todo procedimiento en el que se vaya a elegir el modo de gestión de un servicio público, independientemente de la solución final del mismo, pues serán la base para acreditar que la opción final es la más sostenible y eficiente, tal y como exige el artículo 85 LRBRL.

Por último, en cuanto a la publicidad que se exige si se opta por la gestión a través de Entidad pública empresarial o Sociedad mercantil locales, esta no supone un gravamen en relación al resto de formas de gestión si se parte de la interpretación defendida en este trabajo de los artículos 86 LRBRL y 97 TRRL por

90 SJCA núm. 3 de Valladolid 150/2017, de 14 de noviembre (rec. 14/2017), FJ 5.

91 En concordancia, «la prestación de servicios se realizará normalmente por la propia Administración por sus propios medios. No obstante, cuando carezca de medios suficientes, previa la debida justificación en el expediente, se podrá contratar de conformidad con lo establecido en el Capítulo V del Título II del Libro II de la presente Ley» (artículo 30.3 LCSP). Respecto a este último inciso, resulta llamativo, como destaca Gosálbez Pequeño, «que la norma remite sólo a la regulación específica del contrato de servicios, y no a la regulación de la concesión de servicios que es la heredera cuasiforzosa del derogado contrato de gestión de servicios públicos (ex Disposición adicional trigésima cuarta de la LCSP)». Vid. GOSÁLBEZ PEQUEÑO, H. (2018): "Potestad autoorganizativa, cooperación administrativa y servicios públicos locales”, cit., pág. 188.

92 COLOMÉ I NIN, A. y GRAU I ARNAU, S. (2017): “«Remunicipalización» de servicios locales y competencia”, cit., págs. 131-132.

93 De esta opinión es Gosálbez Pequeño. Vid. GOSÁLBEZ PEQUEÑO, H. (2018): "Potestad autoorganizativa, cooperación administrativa y servicios públicos locales", cit., págs. 191-193. 
REALA. Nueva Época - N.o 12, octubre-marzo 2019 - ISSN: 1989-8975 - DOI: 10.24965/reala.i12.10682 - [Págs. 72-96]

El procedimiento para la remunicipalización de servicios públicos. A propósito de los artículos 85 y $86 L R B R L$

Miguel León Acosta

cuanto aquella será de aplicación tanto a la hora del establecimiento del servicio, como si se pretende cambiar la gestión. Así pues, la publicidad o exposición pública del expediente será obligatoria para cualquier forma de gestión por la que se haya optado, no por exigencia del 85 LRBRL sino por imposición de los artículos 86 LRBRL y 97 TRRL.

\section{CONCLUSIONES}

En el presente trabajo hemos puesto de manifiesto la importancia de la dimensión procedimental del fenómeno de la remunicipalización (o, si se prefiere, reinternalización) de servicios públicos locales, recogida en los artículos 86 LRBR y 97 TRRL. La redacción de estos preceptos plantea dudas sobre la aplicación del procedimiento en ellos regulado a los supuestos de establecimiento de un servicio público de contenido económico, por un lado, y del cambio de gestión de un servicio público que ya se estaba prestando, por el otro. En relación con estas cuestiones controvertidas, hemos tratado de evidenciar que el establecimiento de un servicio público, ya sea de carácter facultativo como obligatorio, debe encuadrarse dentro del ámbito de aplicación de los referidos artículos. Ello es así porque dicha prestación puede suponer un riesgo para la sostenibilidad financiera y el equilibrio presupuestario del conjunto de la Hacienda local y puede afectar a los competidores privados que ya operan en ese mismo sector, por lo que la prestación del mismo no será, per se, conveniente y oportuna, sino que dependerá de cómo se configure en cada caso concreto.

Igualmente y utilizando argumentos similares, entendemos también que el cambio de gestión de un servicio público debe quedar sometido al procedimiento de los artículos 86 LRBRL y 97 TRRL dado que la gestión se configura, en nuestro ordenamiento jurídico, como un elemento principal en la prestación de un servicio público y no como un elemento secundario o accesorio. La configuración de dicha prestación se basa principalmente en cómo se gestione y, por supuesto, esta decisión influirá en todo caso en las finanzas de la Hacienda Local y en la competencia del sector, pudiendo dejar de ser la prestación conveniente y oportuna en esos precisos términos. En esta línea, un aspecto tan importante como la gestión del servicio debe poder ser conocido y valorado por los vecinos (a través del trámite de la exposición pública), del mismo modo que ocurre con el propio establecimiento del servicio.

Por su estrecha vinculación con el procedimiento de los artículos 86 LRBRL y 97 TRRL, el trabajo ha abordado, en su segunda parte, la elección de la forma de gestión del servicio. Dicha elección, tradicionalmente considerada como parte de la potestad de autoorganización de la entidad local, se ha visto radicalmente modificada por la LRSAL. En efecto, esta ley ha modificado la naturaleza de aquella potestad, que ha dejado de ser una potestad discrecional enmarcada en la potestad autoorganizativa de la Administración local [artículos 4.1 a) LRBRL y $30 \mathrm{RSCL}$ ], para convertirse en una potestad reglada en virtud de la cual la Corporación local deberá optar por la forma de gestión más sostenible y eficiente, independientemente de si se trata de un modo de gestión directa o indirecta. Ciertamente, nuestro ordenamiento juridico no es ajeno a los conceptos de sostenibilidad y eficiencia, pues la propia Constitución exige que se tengan en cuenta cuando establece que «la Administración sirve con objetividad los intereses generales» (artículo 103.1 CE), asignando de forma equitativa los recursos de los que dispone (artículo $31.2 \mathrm{CE}$ ). No obstante, la introducción expresa de estos conceptos en el artículo 85 LRBRL y la conversión de la potestad de la Corporación local en una potestad reglada sin duda ha de facilitar el control judicial de esta decisión.

Por otra parte, y a pesar de lo que pueda parecer, no creemos que la LRSAL haya introducido en la LRBRL una preferencia general de las formas de gestón indirecta frente a la gestión directa, ni tampoco al revés. La ley exige que se opte por la forma de gestión más sostenible y eficiente atendiendo al supuesto concreto y a las circunstancias del servicio en cuestión y del Municipio en el que esté implantado o se pretenda implantar. Decisión que, como no puede ser de otro modo, se deberá adoptar a través del correspondiente procedimiento en el que deberán valorarse los diferentes informes que se aporten, la memoria sobre la oportunidad y conveniencia y las alegaciones presentadas, en su caso, durante la exposición pública.

En definitiva, hoy igual que hace cien años, no es posible dar una respuesta clara a la pregunta sobre las bondades o los inconvenientes sobre la (re)municipalización: no cabe un rotundo «sí», ni tampoco un definitivo «no», sino más bien un «depende del caso concreto». Precisamente por este motivo, las previsiones procedimentales devienen esenciales, pues a través del procedimiento que se establezca se adoptará la correspondiente decisión para cada supuesto concreto. 
REALA. Nueva Época - N.o 12, octubre-marzo 2019 - ISSN: 1989-8975 - DOI: 10.24965/reala.i12.10682 - [Págs. 72-96]

El procedimiento para la remunicipalización de servicios públicos. A propósito de los artículos 85 y $86 L R B R L$

Miguel León Acosta

\section{REFERENCIAS BIBLIOGRÁFICAS}

ALEMANY GARCÍAS, J. (2018): La recuperación de los servicios públicos locales. Madrid: Civitas Thomson Reuters.

ARANA GARCÍA, E. (1997): Las sociedades municipales de gestión urbanística. Madrid: Marcial Pons.

AUTORIDAD CATALANA DE LA COMPETENCIA (2015): Ref. núm. OB 19/2015 - INF art 97.2 RDL 781/1986 Santa Maria d'Oló (SG/XP/AC): Informe emitido de conformidad con el artículo 97.2 del Real Decreto Legislativo 781/1986, de 18 de abril, por el cual se aprueba el texto refundido de las disposiciones legales vigentes en materia de régimen local. URL: http://acco.gencat.cat/web/.content/80_acco/documents/arxius/actuacions/Informe-art-972-RD-Leg-781-1986-Sta-Maria-dOlo_CAST.pdf.

BLANQUER CRIADO, D. V. (2012): La concesión de servicio público. Valencia: Tirant lo Blanch.

COLOMÉ I NIN, A. y GRAU I ARNAU, S. (2017): " Remunicipalización» de servicios locales y competencia”, en Cuadernos de Derecho Local QDL, núm. 43, págs. 124-157.

COMISIÓN NACIONAL DE LOS MERCADOS Y LA COMPETENCIA (2013): IPN 088/13: Anteproyecto de la Ley de Racionalización y Sostenibilidad de la Administración local. Informe de Proyecto Normativo. URL: https://www. cnmc.es/sites/default/files/424463_7.pdf.

CONSEJO DE DEFENSA DE LA COMPETENCIA DE ANDALUCÍA (2009): I 03/09: Informe sobre la municipalización del servicio de gestión integral del ciclo del agua en el Municipio de Nerja (Málaga), en régimen de monopolio y mediante gestión indirecta a través de la creación de una sociedad de economía mixta. URL: http://www. juntadeandalucia.es/defensacompetencia/sites/all/themes/competencia/files/pdfs/I_03-09.pdf.

CONSEJO DE ESTADO (2013): Dictamen 567/2013 (Hacienda y Administraciones Públicas) sobre el Anteproyecto de Ley de racionalización y sostenibilidad de la Administración Local. URL: https://www.boe.es/buscar/doc. php?id=CE-D-2013-567\#top.

CORDERO SÁNCHEZ, D. (2016): "Colau apuesta por municipalizar el agua tras la anulación del contrato", en El País, 18 de marzo de 2016. URL: https://elpais.com/ccaa/2016/03/17/catalunya/1458245198_462057.html.

ESTEVE PARDO, J. (2017): "Perspectivas y cauces procedimentales de la remunicipalización de servicios", en Revista de Administración Pública, núm. 202, págs. 305-336. DOI: https://doi.org/10.18042/cepc/rap.202.11.

EZQUERRA HUERVA, A. (2017): "Sobre el procedimiento administrativo a seguir para la remunicipalización de servicios", en Diario La Ley, núm. 8.982, págs. 1-16.

FEDERACIÓN SINDICAL EUROPEA DE SERVICIOS PÚBLICOS (EPSU) (2012): Por qué el agua es un servicio público: destapando los mitos de la privatización. Unidad de Investigación Internacional de Servicios Públicos (PSIRU) de la Universidad de Greenwich. URL: https://www.epsu.org/sites/default/files/article/files/20022012-epsuwater_ES.pdf.

FERNÁNDEZ FARRERES, G. (2007): "Artículo 86”, en REBOLLO PUIG, M. (dir.) e IZQUIERDO CARRASSCO, M. (coord.): Comentarios a la Ley Reguladora de las Bases del Régimen Local, vol. II, págs. 2.302-2.329. Valencia: Tirant lo Blanch.

GARCÍA DE ENTERRÍA, E. y FERNÁNDEZ, T. R. (2015): Curso de Derecho Administrativo, vol. I. Navarra: Civitas Thomson Reuters.

GARCÍA RUBIO, F. (2017): "Pros y contras jurídico-administrativos de la «reinternalización» (remunicipalización) de servicios públicos", en FONT I LLOVET, T. y DÍEZ SÁNCHEZ, J. J. (coords.): Los servicios públicos locales. Remunicipalización y nivel óptimo de gestión: Actas del XXI Congreso de la Asociación Ítalo-Española de Profesores de Derecho administrativo, págs. 173-187. Benidorm-Alicante, 26 a 28 de mayo de 2016. Madrid: lustel y Fundación Democracia y Gobierno Local.

GARRIDO JUNCAL, A. (2016): "Competencias y servicios públicos locales: el nuevo panorama en España tras la LRSAL", en Dereito: Revista Xurídica da Universidade de Santiago de Compostela, vol. 25, núm. extraordinario, XXX Aniversario de la Carta Europea de Autonomía Local, págs. 215-228. DOI: http://dx.doi.org/10.15304/ dereito.25.Ext.3346.

GIMENO FELIU, J. M. (2017): "La remunicipalización de servicios públicos locales: la necesaria depuración de conceptos y los condicionantes jurídicos desde la óptica del derecho europeo", en Cuadernos de Derecho Local QDL, núm. 43, págs. 31-78.

GONZÁLEZ TORROBA, P. (2017): Cuando el Ayuntamiento hace la competencia. Servicio público local y Derecho de la Competencia. Navarra: Thomson Reuters Aranzadi.

GOSÁLBEZ PEQUEÑO, H. (2018): "Potestad autoorganizativa, cooperación administrativa y servicios públicos locales”, en MELLADO RUIZ, L. y FORNIELES GIL, Á. (coords.): Gestión cooperativa en el ámbito local, págs. 175-216. Valencia: Tirant lo Blanch.

GRACIA RETORTILLO, R. (2016): "Racionalización y sostenibilidad de la administración local en España: una reforma frustrada. Las competencias provinciales como paradigma", en Istituzioni del Federalismo: Rivista di Studi Giuridici e Politici, núm. 4, págs. 941-973.

GRACIA RETORTILLO, R. (2016): "La LRSAL ante el Tribunal Constitucional: la afectación a la autonomía local”, en Anuario del Gobierno Local, núm. 1, págs. 225-280.

MAGALDI, N. (2012): "La primera doctrina española sobre la municipalización de servicios públicos: en particular, la recepción de la doctrina extranjera por el profesor Gascón y Marín”, en Revista Aragonesa de Administración Pública, núm. 39-40, págs. 165-219. 
REALA. Nueva Época - N.o 12, octubre-marzo 2019 - ISSN: 1989-8975 - DOI: 10.24965/reala.i12.10682 - [Págs. 72-96]

El procedimiento para la remunicipalización de servicios públicos. A propósito de los artículos 85 y $86 L R B R L$

Miguel León Acosta

MAGALDI, N. (2012): Los orígenes de la municipalización de servicios en España: el tránsito del Estado liberal al Estado social a la luz de la municipalización de servicios públicos. Madrid: Instituto Nacional de Administración Pública INAP.

MALARET I GARCIA, E. (2003): "Servicio público, actividad económica y competencia: ¿presenta especificidades la esfera local?", en Revista de Estudios de la Administración Local y Autonómica REALA, núm. 291, págs. 567-608. DOI: https://doi.org/10.24965/reala.vi291.9190.

MEDINA ALCOZ, L. (2016): "La distribución de competencias entre el Estado y las comunidades autónomas a la luz de las sentencias constitucionales sobre la reforma local de 2013”, en Anuario del Gobierno Local, núm. 1, págs. 189-224.

ORTEGA BERNARDO, J. (2006): "Competencias, servicios públicos y actividad económica de los Municipios: (Presupuestos actuales para su delimitación y su ejercicio)”, en Revista de Administración Pública, núm. 169, págs. 55-98.

ORTEGA BERNARDO, J. (2016): "Derecho de defensa de la competencia y Administraciones Públicas: una visión crítica sobre las excepciones a la aplicación de las normas de la competencia a los Gobiernos Locales", en BAÑO LEÓN, J. M. (coord.): Memorial para la reforma del Estado: estudios en homenaje al Profesor Santiago Muñoz Machado, vol. III, págs. 2.235-2.255. Madrid: Centro de Estudios Políticos y Constitucionales.

ORTEGA BERNARDO, J. y DE SANDE PÉREZ-BEDMAR, M. (2015): "El debate sobre la remunicipalización de los servicios públicos: aspectos jurídicos, administrativos y laborales”, en Anuario de Derecho Municipal, núm. 9 , págs. 63-96.

PONCE SOLÉ, J. (2016): "Remunicipalización y privatización de los servicios públicos y derecho a una buena administración. Análisis teórico y jurisprudencial del rescate de concesiones”, en Cuadernos de Derecho Local QDL, núm. 40, págs. 68-108.

RODRÍGUEZ DE SANTIAGO, J. M. (2016): Metodología del Derecho administrativo: reglas de racionalidad para la adopción y el control de la decisión administrativa. Madrid: Marcial Pons.

SÁNCHEZ DÍAZ, J. L. (2003): "Los servicios locales de naturaleza económica. Municipalización, concesión y autorización", en Revista de Estudios de la Administración Local y Autonómica REALA, núm. 291, págs. 1.0411.062. DOI: https://doi.org/10.24965/reala.vi291.9207.

SOSA WAGNER, F. (2007): "Artículo 85", en REBOLLO PUIG, M. (dir.) e IZQUIERDO CARRASCO, M. (coord.): Comentarios a la Ley Reguladora de las Bases del Régimen Local, vol. II, págs. 2.257-2.300. Valencia: Tirant lo Blanch.

TORNOS MAS, J. (2017): "La llamada remunicipalización de los servicios públicos locales. Algunas precisiones conceptuales", en Cuadernos de Derecho Local QDL, núm. 43, págs. 12-30.

TORNOS MAS, J. (2017): "La remunicipalización de los servicios públicos locales”, en FONT I LLOVET, T. y DÍEZ SÁNCHEZ, J. J. (coords.): Los servicios públicos locales. Remunicipalización y nivel óptimo de gestión: Actas del XXI Congreso de la Asociación Ítalo-Española de Profesores de Derecho administrativo, págs. 21-80. BenidormAlicante, 26 a 28 de mayo de 2016. Madrid: lustel y Fundación Democracia y Gobierno Local.

VELASCO CABALLERO, F. (2016): "Juicio constitucional sobre la LRSAL: punto final”, en Anuario de Derecho Municipal, núm. 10, págs. 22-44.

VILLAR PALASÍ, J. L. (1950): “La actividad industrial del Estado en el Derecho Administrativo”, en Revista de Administración Pública, núm. 3, págs. 53-129.

VILLAR ROJAS, F. J. (2016): "Implicaciones de los principios de sostenibilidad y estabilidad presupuestaria en los modos de gestión de los servicios públicos locales", en El Cronista del Estado Social y Democrático de Derecho, núm. 58-59, págs. 96-106.

WOLLMAN, H. (2013): "La experiencia de los ordenamientos europeos: ¿un "retorno" a las gestiones públicas/ municipales?", en Cuadernos de Derecho Local QDL, núm. 31, págs. 70-80. URL: http://repositorio.gobiernolocal. es/xmlui/handle/10873/1395. 